FEDERAL RESERVE BANK OF SAN FRANCISCO

WORKING PAPER SERIES

\title{
Interest-Rate Liberalization and Capital Misallocations
}

\author{
Zheng Liu \\ Federal Reserve Bank of San Francisco \\ Pengfei Wang \\ Hong Kong University of Sciences and Technology \\ Zhiwei Xu \\ Shanghai Jiao Tong University \\ January 2020 \\ Working Paper 2017-15 \\ http://www.frbsf.org/economic-research/publications/working-papers/wp2017-15.pdf
}

\section{Suggested citation:}

Liu, Zheng, Pengfei Wang, Zhiwei Xu. 2020. “Interest-Rate Liberalization and Capital Misallocations,” Federal Reserve Bank of San Francisco Working Paper 2017-15.

https://doi.org/10.24148/wp2017-15

The views in this paper are solely the responsibility of the authors and should not be interpreted as reflecting the views of the Federal Reserve Bank of San Francisco or the Board of Governors of the Federal Reserve System. This paper was produced under the auspices of the Center for Pacific Basin Studies within the Economic Research Department of the Federal Reserve Bank of San Francisco. 


\title{
INTEREST-RATE LIBERALIZATION AND CAPITAL MISALLOCATIONS
}

\author{
ZHENG LIU, PENGFEI WANG, AND ZHIWEI XU
}

\begin{abstract}
We study the consequences of interest-rate liberalization in a two-sector general equilibrium model of China. The model captures a key feature of China's distorted financial system: state-owned enterprises (SOEs) have greater incentive to expand production and easier access to credit than private firms. In this second-best environment, interest-rate liberalization can improve capital allocations within each sector, but can also exacerbate misallocations across sectors. Under calibrated parameters, the liberalization policy can reduce aggregate productivity and welfare unless other policy reforms are also implemented to alleviate SOEs' distorted incentives or improve private firms' credit access.
\end{abstract}

\section{INTRODUCTION}

The Chinese government has maintained tight controls over domestic interest rates. The People's Bank of China (PBOC), the country's central bank, sets the benchmark lending and deposit rates for all financial institutions in China. The PBOC has permitted banks to offer a range of deposit and lending rates within a relatively narrow band, and it has adjusted the bands occasionally. Interest rate controls create a wedge between the two types of interest rates (see Figure 1). In 2013, the PBOC liberalized controls over bank lending rates. In 2015, the PBOC further widened the range of deposit rates that banks can offer. According to the standard theory, such interest-rate liberalization should reduce financial frictions and

Date: January 28, 2020.

Key words and phrases. Interest rate controls, financial frictions, SOE reforms, capital misallocation, total factor productivity, welfare.

JEL classification: E44, G18, O41.

Liu: Federal Reserve Bank of San Francisco; Email: zliu001@gmail.com. Wang: Hong Kong University of Sciences and Technology and Peking University HSBC Business School; Email: pfwanghkust@gmail.com. Xu: Shanghai Jiao Tong University; Email: xuzhiwei09@gmail.com. For helpful comments, we are grateful to Hanming Fang, Chad Jones, John Leahy, Ernest Liu, Jianjun Miao, Jun Qian, Michael Zheng Song, Mark Spiegel, Shang-Jin Wei, Tao Zha, and Xiaodong Zhu. We also thank seminar participants at the 2018 ABFER conference, the 2017 Asian Meeting of the Econometric Society, the Chinese University of Hong Kong, the Federal Reserve Bank of San Francisco, the IMF, Hong Kong University of Science and Technology, Hong Kong Baptist University, the 2017 NBER Chinese Economy Working Group meeting in Shenzhen, Peking University, Shanghai Jiao Tong University, SAIF, Shanghai University of Finance and Economics, Southwest University of Finance and Economics, and Zhejiang University for comments. We thank Anita Todd for helpful editorial assistance. The research is supported by the National Natural Science Foundation of China Project Number 71633003. The views expressed in this paper are those of the authors and do not necessarily reflect the views of the Federal Reserve Bank of San Francisco or the Federal Reserve System. 
thus improve capital allocation; this should lead to higher aggregate productivity and social welfare (e.g., Hsieh and Klenow, 2009; Buera et al., 2011; Midrigan and Xu, 2014; Moll, 2014).

We argue in this paper that interest-rate liberalization may not improve aggregate productivity and welfare in China unless other distortions in the economy can be mitigated or eliminated. In a second-best environment with multiple sources of distortions, the full consequences of interest-rate liberalization can be understood only in a general equilibrium framework that takes into account other existing distortions in China.

We provide such a framework. In particular, we build a two-sector dynamic general equilibrium model to study the macroeconomic implications of interest-rate liberalization in a second-best environment. Our model captures some important features of the existing distortions facing China's financial system. In the model, final goods are produced by firms in two sectors: one sector with state-owned enterprises (SOEs) and the other with private firms (POEs). Consistent with empirical evidence, we assume that SOEs are on average less productive than POEs (Hsieh and Klenow, 2009).

Despite their lower productivity, SOEs can survive in our model because of favorable government policy. Consistent with the institutional features of the Chinese economy, we assume that the government provides production subsidies to SOEs and grants them with favorable credit access. These policies are implemented in China, partly because the country does not have a reliable social safety net, and the government requires SOEs to help provide social insurance and other public goods. Thus, SOEs face not just the task of profit maximizing but also the task of maintaining employment and providing public goods. For this reason, the government does not want to shut down unprofitable SOEs; instead, it provides various forms of subsidies to SOEs (Bai et al., 2000). Furthermore, SOEs in our model also have easier access to credit than POEs, potentially stemming from government guarantees of SOE debt (Song et al., 2011; Chang et al., 2019). ${ }^{1}$

Within our general equilibrium framework, we study the consequences of interest-rate liberalization for capital allocations and productivity. In the benchmark model with interestrate controls, we assume that government policy creates a wedge between the deposit interest rate and the lending rate. In the case with constant returns technology, heterogeneous productivity, and credit constraints, our analytical results show that the presence of the interest-rate wedge leads to three types of firms within each sector. Firms with sufficiently

\footnotetext{
${ }^{1}$ Brandt and Zhu (2000) argue that the Chinese government's favorable policy towards the SOE sector in the form of cheap credits from state-owned banks and money creation by the People's Bank of China helps explain the observation that the SOE output share in the economy has declined steadily since the early 1980s, while the SOE employment and investment shares have remained relatively high.
} 
high productivity choose to operate, with production financed by both internal funds and external debt. For each of these firms, the marginal product of capital (MPK) exceeds the loan rate and thus external financing is profitable. In the other extreme, firms with sufficiently low productivity choose to save, since their MPKs are below the deposit rate and thus saving gives them a higher return than operating. Firms with intermediate levels of productivity choose to operate and self finance because their MPKs lie between the deposit rate and the loan rate.

When liberalization policy removes the interest-rate wedge, the loan and deposit rates converge to a single interest rate, and the distribution of firms collapses to two types from three. High-productivity firms choose to operate and use both internal funds and external debt to finance their operation. Low-productivity firms choose to save (and do not produce) because their MPKs are below the market interest rate. With the exception of the marginal firm, no firms would choose to self-finance their production. Compared with the benchmark case with interest-rate controls, the marginal firm now has higher productivity. Therefore, the liberalization policy improves productivity within each sector. This implication of interestrate liberalization is similar to that found in the literature with heterogeneous firms and financial frictions in one-sector models (Moll, 2014).

However, the liberalization policy exacerbates capital misallocation across sectors. With a higher deposit rate, aggregate savings rise. The increased savings flow disproportionately to the SOE sector because SOE firms have an incentive to expand production scales and also have easier access to credit than POEs. Reallocation of capital from POEs to SOEs reduces aggregate productivity because SOE firms have lower average productivity than POE firms.

Overall, interest-rate liberalization has an ambiguous net effect on aggregate productivity and welfare in this second-best environment. To assess the net effect of the liberalization reform, we study a calibrated dynamic version of the model. Unlike the analytical baseline with a constant-returns technology and a fixed supply of capital, we assume that, in the dynamic model, firms operate a decreasing returns technology and endogenously accumulate capital (Midrigan and $\mathrm{Xu}, 2014){ }^{2}$ We calibrate the dynamic model using both aggregate and firm-level Chinese data. Based on the calibrated parameters, we compute the transition dynamics from the current steady state with an interest-rate wedge to a new steady state with the wedge removed.

\footnotetext{
${ }^{2}$ In the baseline analytical model with constant returns, all borrowing firms face binding credit constraints and all saving firms choose not to produce. This feature helps simplify the analytics, but it may overstate the misallocation effects following an interest-rate liberalization. In our dynamic model with decreasing returns, a fraction of borrowing firms chooses to hold an optimal amount of loan, and only firms with sufficiently high productivity face binding credit constraints. In addition, all firms, including those who choose to save, would be active in production because of the diminishing marginal product of capital.
} 
We find that, following a permanent removal of the interest-rate wedge, aggregate total factor productivity (TFP) initially declines, and then rises gradually to a permanently higher level. The initial decline in TFP suggests that the between-sector misallocation of capital dominates the within-sector improvement in allocation in the short run. Consistent with our analytical results, removing the interest-rate wedge improves TFP within each sector, but it also leads to an increase in the share of capital held by the SOE sector. This misallocation across sectors leads to a temporary reduction in both aggregate TFP and aggregate output. Over time, however, output rises because the increase in the deposit interest rate induces more savings and thus more capital accumulation, and also because aggregate TFP rises over time.

By reallocating capital to SOEs, the liberalization policy exacerbates the SOE overinvestment problem, leading a short-run decline in consumption under our calibration. Consistent with our analytical findings, interest-rate liberalization can improve or reduce welfare along the transition path, depending on the initial size of the interest-rate wedge. For example, if the initial wedge is at our calibrated value of 0.032 , then removing the wedge would lead to a modest welfare loss equivalent to about 0.32 percent of steady-state consumption per year. If the initial wedge is 0.05 , then removing the wedge would improve welfare modestly. For larger sizes of the initial interest-rate wedge, liberalization policy can lead to more substantive welfare gains.

The nonlinear welfare effects of interest-rate liberalization reflect a tradeoff between two conflicting forces underlying the economy: within-sector productivity improvements working against between-sector capital misallocations. The tradeoff stems from distortionary government policies that favor SOEs. In two counterfactuals where we eliminate preferential subsidies to SOEs or equalize credit access in the two sectors, we find that the tradeoff facing interest-rate liberalization is substantially mitigated.

We corroborate our model's mechanism with micro-level empirical evidence. We use a panel of industries constructed from the Annual Survey of Industries conducted by China's National Bureau of Statistics for the period from 1998 to 2007 to examine how changes in the interest-rate wedge are related to industry-level productivity, and how the presence of distorted allocations can affect that relation. We find that, all else being equal, a decline in the interest-rate wedge raises productivity; but in industries with distorted allocations, a decline in the interest-rate wedge would reduce productivity. These findings are consistent with our model's predictions. ${ }^{3}$

\footnotetext{
${ }^{3}$ It is difficult to use aggregate time-series data to isolate the effects of interest-rate liberalization on capital reallocations, because the liberalization reforms were not implemented until very recently (in 2015), with the potential macro effects yet to be fully materialized. During this period, China has also implemented several
} 
Several independent studies also lend support to our model's mechanism. These studies find that financial liberalization in China improved within-sector capital allocations but worsened capital allocations across sectors. For example, Gao et al. (2017) examine the effects of the 2009 bank entry deregulation in China using loan-level and firm-level data. They document evidence that, following the deregulation, most loans originated from new entrant banks went to SOEs, which had explicit or implicit government guarantees and are thus considered "safe" borrowers. At the same time, the deregulation of bank entry led to increased competition between new and incumbent banks, which raised the overall quality of all loans, with significantly longer maturity and lower delinquency rates. Increased bank competition following the 2009 banking deregulation also led to improvements in the efficiency of firms that borrowed from banks, with private firms benefiting more than SOEs. In another study, Cong et al. (2018) examine loan-level data and find that the credit expansion during China's large-scale fiscal stimulus period in 2009-2010 disproportionally favored state-owned firms despite their lower average product of capital. These empirical findings are broadly consistent with our model's implications.

In what follows, Section II provides an analytical illustration of how interest-rate liberalization can affect within- and between-sector capital allocations and aggregate productivity. Section III presents a calibrated dynamic model with endogenous capital accumulations and decreasing returns and studies the transition dynamics and welfare following an interest-rate liberalization. Section IV provides some empirical support for our model's mechanism based on Chinese industry-level data. We discuss the contributions of our paper relative to the literature in Section V and provide some concluding remarks in Section VI.

\section{A Static Model}

This section presents a simple static two-sector model to highlight the tradeoff for interestrate liberalization between within-sector and between-sector capital allocations.

In the economy, a homogeneous good is produced by firms in two sectors - an SOE sector (sector $s$ ) and a POE sector (sector $p$ ). There is a continuum of firms within each sector, with a measure $\mu$ of firms in the SOE sector and $1-\mu$ in the POE sector. Firms in each sector have access to a constant-returns technology that transforms capital into a homogeneous final good. Each firm is endowed with $h$ units of capital. The efficiency of a firm's production in each sector is determined by both a sector-specific productivity and an idiosyncratic productivity. Firms also have access to a financial market where they can borrow or lend.

other important policy reforms, further compounding the difficulty. The micro-level data that we use here are better suited for studying the reallocation consequences of changes in the interest-rate wedge. 
Under interest-rate controls, the government maintains a wedge $\phi>0$ between the deposit rate $\left(r_{d}\right)$ and the lending rate $\left(r_{l}\right)$. Thus, we have

$$
r_{l}=r_{d}+\phi
$$

Throughout the paper, interest-rate liberalization means the removal of the wedge (i.e., setting $\phi=0){ }^{4}$

II.1. Firms in the POE sector. A firm in the POE sector with idiosyncratic productivity $\varepsilon$ chooses capital $k^{p}(\varepsilon)$, savings $s^{p}(\varepsilon)$ or loans $l^{p}(\varepsilon)$ to maximize its profit

$$
z^{p} \varepsilon k^{p}(\varepsilon)-r_{l} l^{p}(\varepsilon)+r_{d} s^{p}(\varepsilon),
$$

where $z^{p}$ denotes a sector-specific productivity. The idiosyncratic productivity $\varepsilon$ is drawn from the distribution $\mathbf{F}^{p}(\varepsilon)$.

The firm faces the flow-of-funds constraint

$$
k^{p}(\varepsilon)=h+l^{p}(\varepsilon)-s^{p}(\varepsilon),
$$

and the borrowing constraint

$$
0 \leq l^{p}(\varepsilon) \leq \theta^{p} h
$$

where $\theta^{p}$ denotes the loan-to-value ratio.

If the firm chooses to save, its saving cannot exceed the total endowment. Thus, the firm also faces the saving constraint

$$
0 \leq s^{p}(\varepsilon) \leq h
$$

II.2. Firms in the SOE sector. An SOE firm with the idiosyncratic productivity $\varepsilon$ chooses capital $k^{s}(\varepsilon)$, saving $s^{s}(\varepsilon)$, and borrowing $l^{s}(\varepsilon)$ to maximize the objective function

$$
\tau z^{s} \varepsilon k^{s}(\varepsilon)-r_{l} l^{s}(\varepsilon)+r_{d} s^{s}(\varepsilon)
$$

where $\tau>1$ represents distortions to SOE incentives (e.g., government subsidies to SOEs), $z^{s}$ denotes a sector-specific production, and the idiosyncratic productivity $\varepsilon$ is drawn from the distribution $\mathbf{F}^{s}(\varepsilon)$.

\footnotetext{
${ }^{4}$ The parameter $\phi$ is a parsimonious way of capturing interest rate controls in China. Under our specification, one of the interest rates (e.g., the deposit rate) is determined endogenously by the loan market-clearing condition, and the other rate (e.g., the lending rate) is then pinned down by the policy wedge $\phi$. The constant interest-rate wedge here is not crucial for deriving our results. It is easy to show that this setup is equivalent to one in which the government controls the deposit rate $r_{d}$, while the lending rate $r_{l}$ and the interest-rate wedge are determined endogenously (this can be shown using the results stated in Proposition 4).
} 
Under our assumption that $\tau>1$, SOEs have an incentive to expand production beyond that motivated by profit maximizing. ${ }^{5}$ The distorted SOE incentive here is consistent with the multitask principal-agent theory of SOEs in the literature (Bai et al., 2000). In China, SOE managers are appointed by the government and their performance is evaluated partly based on the firm's contributions to local GDP and employment targets, not just on profits. To prevent unprofitable SOEs from exiting business, the government provides subsidies to SOE output. The setup here is also consistent with the "soft budget constraint" theory for SOEs, which argues that the state should be accountable for the poor performance of SOEs since it imposes extra policy burdens on them. In compensation, the state subsidizes SOE operations(Lin et al., 1998; Lin and Tan, 1999).

The SOE firm's optimizing decision is subject to the flow-of-funds constraint

$$
k^{s}(\varepsilon)=h+l^{s}(\varepsilon)-s^{s}(\varepsilon)
$$

and the constraints on borrowing and saving

$$
\begin{aligned}
& 0 \leq l^{s}(\varepsilon) \leq \theta^{s} h \\
& 0 \leq s^{s}(\varepsilon) \leq h
\end{aligned}
$$

where $\theta^{s}$ denotes the loan-to-value ratio for SOEs.

For analytical convenience, we normalize the mean of the idiosyncratic productivity in each sector to one. Consistent with empirical evidence, we assume that SOEs have easier access to credit than POEs, so that $\theta^{p}<\theta^{s}$. We also assume that SOEs are less productive than POEs on average, so that $z^{s}<z^{p}$.

II.3. Equilibrium. An equilibrium consists of the deposit rate $r_{d}$, the loan rate $r_{l}$, and the allocations $\left\{k^{s}(\varepsilon), l^{s}(\varepsilon), s^{s}(\varepsilon)\right\}$ for each SOE firm indexed by $\varepsilon \sim \mathbf{F}^{s}(\varepsilon)$ and $\left\{k^{p}(\varepsilon), l^{p}(\varepsilon), s^{p}(\varepsilon)\right\}$ for each POE firm indexed by $\varepsilon \sim \mathbf{F}^{p}(\varepsilon)$, such that (i) the allocations for each firm in each sector solve the firm's optimizing problem, and (ii) capital market clears such that

$$
\mu \int k^{s}(\varepsilon) d \mathbf{F}^{s}(\varepsilon)+(1-\mu) \int k^{p}(\varepsilon) d \mathbf{F}^{p}(\varepsilon)=h
$$

Aggregate output is given by

$$
Y=\mu \int z^{s} \varepsilon k^{s}(\varepsilon) d \mathbf{F}^{s}(\varepsilon)+(1-\mu) \int z^{p} \varepsilon k^{p}(\varepsilon) d \mathbf{F}^{p}(\varepsilon) .
$$

II.4. Effects of liberalization. We use this simple static model to illustrate the impact of interest-rate liberalization on steady-state capital allocations and productivity.

\footnotetext{
${ }^{5}$ The SOE subsidy $\tau>1$ captures several sources of distortions, such as SOEs' monopoly rents (Li et al., 2015) or fixed costs (Song and Hsieh, 2015), in addition to explicit or implicit government subsidies.
} 
II.4.1. Homogeneous firms. We first examine the implications of a liberalization policy for between-sector allocations of capital. For this purpose, we consider the special case with no idiosyncratic productivities, so that firms in each sector are homogenenous. In this case, changes in aggregate productivity following a liberalization policy would be driven purely by between-sector reallocations of capital between SOEs and POEs. ${ }^{6}$

For analytical convenience, we assume the existence of a sufficiently large SOE subsidy rate such that $\tau z^{s}>z^{p}>z^{s}$. This subsidy makes the representative SOE firm's private marginal product of capital (inclusive of government subsidies) higher than the representative POE firm's MPK. We also assume that the pre-reform economy has a sufficiently large interestrate wedge such that $\phi>\tau z^{s}-z^{p}$. Under these assumptions, the pre-reform equilibrium is a financial autarky, as we show in Proposition 1.

Proposition 1. Assume that $\tau z^{s}>z^{p}>z^{s}$ and $\phi>\tau z^{s}-z^{p}$. The only equilibrium in this economy is one with financial autarky, with $r_{d} \in\left[\tau z^{s}-\phi, z^{p}\right]$. Equilibrium capital allocations are given by

$$
k^{p}=k^{s}=h .
$$

Equilibrium aggregate output is given by

$$
Y=(1-\mu) z^{p} h+\mu z^{s} h
$$

Proof. We provide a formal proof in Appendix A.

The intuition of the proof is simple. If the deposit and lending rates are too high, then all firms would want to save, which would not be an equilibrium since it violates the loan market-clearing condition. On the other hand, if the interest rates are too low, then all firms would want to borrow, which again violates the loan market-clearing condition. Only when the deposit interest rate lies in an intermediate range (in particular, $r^{d} \in\left[\tau z^{s}-\phi, z^{p}\right]$ ) would there be an equilibrium, which puts the economy in a financial autarky.

When interest-rate controls are liberalized (i.e., $\phi=0$ ), the equilibrium allocations are in general different from the autarkic allocations. As we show below in Proposition 2, if SOEs have a sufficiently large borrowing capacity relative to the sector's size, then all capital in the economy would flow to the SOE sector after the liberalization. If SOEs face a relatively tight borrowing constraint, then some capital would flow from POEs to SOEs (up to the SOEs' borrowing limit) and firms in both sectors would be active in production. Furthermore, since SOEs are less productive than POEs, reallocating capital from POEs to SOEs reduces aggregate output and productivity relative to the pre-reform benchmark (which is a financial autarky). This last result is summarized in Corollary 1.

\footnotetext{
${ }^{6}$ In this simple model, aggregate capital stock equals the endowment $h$. Thus, changes in output and changes in aggregate productivity are equivalent.
} 
Proposition 2. In the liberalized economy with $\phi=0$, the deposit rate and lending rate are identical and the equilibrium interest rate lies in the interval $\left[z^{p}, \tau z^{s}\right]$. Equilibrium capital allocations are given by

$$
\begin{aligned}
k^{p} & =\frac{1-\mu\left(1+\theta^{s}\right)}{1-\mu} h<h, \\
k^{s} & =\left(1+\theta^{s}\right) h>h,
\end{aligned}
$$

and aggregate output $Y$ is given by

$$
Y=\left\{\begin{array}{cl}
z^{p} h-\left(z^{p}-z^{s}\right) \mu\left(1+\theta^{s}\right) h & \text { if } \theta^{s}<1 / \mu-1, \\
z^{s} h & \text { if } \theta^{s} \geq 1 / \mu-1 .
\end{array}\right.
$$

Proof. See Appendix A.

Compared to the pre-reform benchmark (which is a financial autarky), interest-rate liberalization reduces capital used by the POEs and increases capital used by the SOEs. Since the SOEs are less productive, this reallocation of capital reduces aggregate output and productivity. Formally, one can use Equations (13) and (16) to verify that aggregate output in the economy with liberalized interest rates is lower than that under interest-rate controls. Therefore, in this economy with homogeneous firms within each sector, removing interestrate controls unambiguously reduces aggregate output. Since aggregate capital stock is fixed at $h$, the liberalization policy also reduces aggregate total factor productivity (TFP). This result is stated in Corollary 1.

Corollary 1. With homogeneous firms within each sector, aggregate output and TFP are lower in the economy with liberalized interest rates $(\phi=0)$ than those under interest-rate controls $(\phi>0)$.

The finding that liberalizing interest-rate controls reduces aggregate output and TFP is surprising, but economically intuitive in this second-best environment. When interest-rate controls are lifted, the deposit interest rate rises and the loan rate falls. In our simple model, the deposit rate rises to levels above the MPK for the POEs, inducing POEs to save. The decline in the loan rate along with government subsidies would provide an incentive for SOEs to borrow. Since POEs are more productive than SOEs, capital flows from POEs to SOEs represent a misallocation of resources that reduces aggregate output and TFP.

If firms within each sector have heterogeneous productivity, then interest-rate liberalization can improve within-sector capital allocation and offset (at least partially) the adverse impact of the between-sector misallocation on aggregate productivity, as we discuss in the next section. 
II.4.2. Heterogeneous firms. Consider the case where firms in each sector face idiosyncratic productivity shocks drawn from the distribution $\mathbf{F}^{j}(\varepsilon)$, with the support $\left[\varepsilon_{\min }, \infty\right)$. The following proposition characterizes the equilibrium allocations of credit and capital.

Proposition 3. In the economy with heterogeneous firms, there exist two threshold levels of idiosyncratic productivity, denoted by $\underline{\varepsilon}^{j}$ and $\bar{\varepsilon}^{j}$ for each sector $j \in\{s, p\}$, such that

$$
\begin{aligned}
& s^{j}(\varepsilon)=\left\{\begin{array}{ll}
h & \text { if } \varepsilon_{\min } \leq \varepsilon<\underline{\varepsilon}^{j} \\
0 & \text { if } \underline{\varepsilon}^{j} \leq \varepsilon
\end{array},\right. \\
& l^{j}(\varepsilon)=\left\{\begin{array}{cc}
0 & \text { if } \varepsilon_{\min } \leq \varepsilon<\bar{\varepsilon}^{j} \\
\theta^{j} h & \text { if } \bar{\varepsilon}^{j} \leq \varepsilon
\end{array},\right. \\
& k^{j}(\varepsilon)=\left\{\begin{array}{cc}
0 & \text { if } \varepsilon_{\min } \leq \varepsilon<\underline{\varepsilon}^{j} \\
h & \text { if } \underline{\varepsilon}^{j} \leq \varepsilon<\bar{\varepsilon}^{j} \\
\left(1+\theta^{j}\right) h & \text { if } \bar{\varepsilon}^{j} \leq \varepsilon
\end{array} .\right.
\end{aligned}
$$

The thresholds $\underline{\varepsilon}^{j}$ and $\bar{\varepsilon}^{j}$ are defined as

$$
\begin{aligned}
& \underline{\varepsilon}^{j}=\frac{r_{d}}{z^{j} \tau^{j}}, \\
& \bar{\varepsilon}^{j}=\frac{r_{d}+\phi}{z^{j} \tau^{j}},
\end{aligned}
$$

where $\tau^{j}$ denotes the output subsidy rates for sector $j$ (and we normalize sector $p$ subsidies to $\left.\tau^{p}=1\right)$.

Proof. We provide a proof in Appendix A.

Proposition 3 shows that, under interest-rate controls, the wedge between the lending and deposit rates imply that there are three different types of firms. Firms with sufficiently high productivity choose to produce using both internal funds and external debt. Firms with sufficiently low productivity choose to save instead of producing. Firms with intermediate levels of productivity choose to produce, and finance their production with internal funds only.

The equilibrium deposit rate (or the lending rate) is determined by the capital marketclearing condition

$$
K=(1-\mu) K^{p}+\mu K^{s}=h,
$$

where $K^{j}$ denotes aggregate demand for capital in section $j \in\{s, p\}$ given by

$$
K^{j}=\left[\int_{\underline{\underline{\varepsilon}}^{j}}^{\bar{\varepsilon}^{j}} d \mathbf{F}(\varepsilon)+\left(1+\theta^{j}\right) \int_{\bar{\varepsilon}^{j}}^{\infty} d \mathbf{F}(\varepsilon)\right] h .
$$


It is easy to show that aggregate output in section $j \in\{s, p\}$ is related to the sector's aggregate capital input through

$$
Y^{j}=A^{j} K^{j},
$$

where the term $A^{j}$ denotes sector $j$ 's TFP given by

$$
A^{j}=z^{j} \frac{\int_{\underline{\varepsilon}^{j}}^{\bar{\varepsilon}^{j}} \varepsilon d \mathbf{F}(\varepsilon)+\left(1+\theta^{j}\right) \int_{\bar{\varepsilon}^{j}}^{\infty} \varepsilon d \mathbf{F}(\varepsilon)}{\int_{\underline{\varepsilon}^{j}}^{\bar{\varepsilon}^{j}} d \mathbf{F}(\varepsilon)+\left(1+\theta^{j}\right) \int_{\bar{\varepsilon}^{j}}^{\infty} d \mathbf{F}(\varepsilon)} .
$$

Thus, sector $j$ 's TFP contains both the exogenous component $z^{j}$ and an endogenous component. The endogenous component of the sectoral TFP stems from within-sector reallocations of capital across firms with different idiosyncratic productivity, and its level depends on the two threshold values $\underline{\varepsilon}^{j}$ and $\bar{\varepsilon}^{j}$. Proposition 3 shows that those threshold values are functions of the equilibrium deposit rate $r_{d}$, which itself is a function of the policy wedge $\phi$, along with other parameters in the model.

When interest-rate liberalization removes the wedge $\phi$ between the lending and deposit rates, Proposition 3 shows that the two threshold levels of productivity $\underline{\varepsilon}^{j}$ and $\bar{\varepsilon}^{j}$ would coincide, and the distribution of firms would collapse to two types from three. The following proposition shows that the liberalization policy raises the deposit rate and reduces the lending rate, so that the two interest rates converge.

Proposition 4. The deposit rate $r_{d}$ decreases with the interest-rate wedge $\phi$ and the lending rate $r_{l}$ increases with $\phi$. Thus, interest-rate liberalization (that lowers $\phi$ ) would raise the deposit rate $r_{d}$ and reduce the lending rate $r_{l}$.

Proof. See Appendix A.

To the extent that interest-rate liberalization changes equilibrium deposit and lending rates, it also affects sectoral TFP through reallocating capital across firms within each sector. In addition, interest-rate liberalization affects aggregate TFP through reallocating capital across the two sectors. Since aggregate capital supply is fixed (at $h$ ), aggregate TFP moves one-for-one with aggregate output.

Specifically, aggregate output is given by

$$
Y=A^{s} K+\left(A^{p}-A^{s}\right)(1-\mu) K^{p} .
$$

Aggregate TFP is given by

$$
\mathrm{TFP}=\frac{Y}{K}=A^{s}+\left(A^{p}-A^{s}\right)(1-\mu) \frac{K^{p}}{h} .
$$

Thus, given the sectoral TFPs $A^{s}$ and $A^{p}$ and that $A^{p}>A^{s}$, a policy reform that leads to capital flows from POEs to SOEs would reduce aggregate TFP. The next proposition 
provides the conditions under which such between-sector misallocations can occur following interest-rate liberalization.

Proposition 5. Assume that the idiosyncratic shocks in the two sectors are drawn from the same distribution, with the probability density function $f(\varepsilon)$. Assume further that the density function satisfies the condition that $g(\varepsilon) \equiv \frac{f^{\prime}(\varepsilon) \varepsilon}{f(\varepsilon)}$ decreases with $\varepsilon$. Under these conditions, we obtain

$$
\frac{\partial K^{s}}{\partial \phi}<0, \quad \frac{\partial K^{p}}{\partial \phi}>0
$$

We also obtain $\frac{\partial A^{p}}{\partial \phi}<0$ whereas $\frac{\partial A^{s}}{\partial \phi}$ has an ambiguous sign. Furthermore, the relation between aggregate output and the interest-rate wedge is also ambiguous (i.e., $\frac{\partial Y}{\partial \phi}$ has an ambiguous sign). The same is true for aggregate TFP.

Proof. See Appendix A.

Proposition 5 shows that a liberalization policy that reduces $\phi$ would lead to capital flows from POEs to SOEs. Although such liberalization improves the level of TFP in the POE sector, it has ambiguous effects on the TFP of the SOE sector. This ambiguity arises because, although the liberalization policy turns some low-productivity SOE firms into savers (by raising the deposit rate), it also attracts capital inflows to the SOE sector, with the increased capital distributed across all active firms, including unproductive ones. The liberalization policy leads to ambiguous effects on aggregate output and aggregate TFP, because of the offsetting roles played by the within-sector improvement in capital allocations and the between-sector deterioration.

Thus, the overall macro impact of interest-rate liberalization depends on the parameter values. To illustrate the non-monotonic relations between the interest-rate wedge and aggregate output, we provide a numerical example. We set $\frac{z^{p}}{z^{s}}=2, \frac{\theta^{s}}{\theta^{p}}=2, \tau=2, \mu=0.5$, and $\theta^{p}=0.3$. We assume that the idiosyncratic shocks are drawn from the log-normal distribution with a mean value of one and a standard deviation of $0.3 .{ }^{7}$

Figure 2 shows the relation between aggregate output (or equivalently, aggregate TFP) and the interest-rate wedge $\phi$. In this numerical example, we obtain a hump-shaped relation between aggregate output and the interest-rate wedge, and there exists an interior optimum of $\phi$ that maximizes output. The result reflects the tradeoff between within- and betweensector capital reallocations following interest-rate liberalization.

\footnotetext{
${ }^{7}$ These parameter values are broadly in line with our calibration in the dynamic model presented in Section III.
} 


\section{INTEREST-RATE LIBERALIZATION AND TRANSITION DYNAMICS}

In our steady-state analysis above, we have assumed that individual firms operate a constant-returns technology, with a fixed supply of capital. These assumptions help simplify our model and enable us to obtain analytical results, but they are not innocuous. With a constant-returns technology, the marginal product of capital does not diminish when firms increase their capital input. Since SOEs receive government subsidies and have easier access to credit, they start out with more holdings of capital. Following the interest-rate liberalization, SOEs would still want to borrow more, exacerbating misallocations across sectors. If the production technology exhibits decreasing returns to scale, however, SOEs with abundant capital would have less incentive to borrow when the loan interest rate declines. In this sense, the constant-returns assumption may overstate the misallocation effects of interestrate liberalization. Introducing endogenous capital accumulation may also affect the model's mechanism because savings can be allocated not just across firms and sectors, but also across time. In this case, an increase in the deposit interest rate following the liberalization reform would raise savings and capital accumulation.

In this section, we generalize our model to incorporate capital accumulation and decreasing returns. We calibrate the model parameters to Chinese data and study transition dynamics following interest-rate liberalization.

III.1. The dynamic model. The main features of the model are similar to the baseline static model, with three key differences. First, individual firms in each sector operate a decreasing-returns technology. Second, we introduce endogenous capital accumulation decisions. Third, production requires not only capital but also labor as input factors, with labor supplied by households. The households own all firms and financial intermediaries. The government subsidizes SOE production, with the subsidies financed by lump-sum taxes imposed on the households.

III.1.1. The households. There is a continuum of identical and infinitely lived households with measure one. The representative household supplies inelastically one unit of labor to firms. The household chooses consumption $C_{t}$, risk-free bond $B_{t+1}$, and share holdings of

individual firms $x_{i, t+1}^{j}$ (where $i$ indicates the firm and $j \in\{s, p\}$ indicates the sector) to maximize the discounted utility

$$
\sum_{t=0}^{\infty} \beta^{t} \log C_{t}
$$

subject to the sequence of budget constraints

$$
C_{t}+\frac{B_{t+1}}{1+r_{d t}}+\sum_{j=\{s, p\}} \int x_{i, t+1}^{j}\left(P_{i t}^{j}-d_{i t}^{j}\right) d i \leq W_{t} N_{t}+B_{t}+\sum_{j=\{s, p\}} \int x_{i t}^{j} P_{i t}^{j} d i-T_{t},
$$


where $d_{i t}^{j}$ and $P_{i t}^{j}$ respectively denote the dividend payouts and the share price of firm $i$ in sector $j, W_{t}$ denotes the real wage rate, $N_{t}=1$ denotes labor supply, and $T_{t}$ denotes the lump sum taxes levied by the government for financing subsidies to SOEs net of dividends received from financial intermediaries. The household also faces the borrowing constraint

$$
\frac{B_{t+1}}{1+r_{d t}} \geq 0 \text {. }
$$

The optimal bond-holding decision implies that

$$
\Lambda_{t}=\beta\left(1+r_{d t}\right) \Lambda_{t+1}+\xi_{t},
$$

where $\Lambda_{t}=\frac{1}{C_{t}}$ and $\xi_{t}$ is the Lagrangian multiplier for the borrowing constraint (31). If the borrowing constraint is binding, then we have $\xi_{t}>0$.

The optimal stock-holding decision implies that

$$
P_{i t}^{j}=d_{i t}^{j}+\beta \frac{\Lambda_{t+1}}{\Lambda_{t}} P_{i t+1}^{j} .
$$

In a symmetric equilibrium, we have $x_{i, t+1}^{j}=1$ for all $i$ and $j$. Interest-rate controls depress the deposit interest rate $r_{d t}$, and the household borrowing constraint (31) becomes binding. Thus, we have $\xi_{t}>0$ and $B_{t+1}=0$ in the equilibrium.

III.1.2. The firms. A firm in sector $j \in\{s, p\}$ operates a decreasing-returns technology

$$
y_{t}^{j}=\left[\left(z^{j} \varepsilon_{t}^{j} k_{t}^{j}\right)^{\alpha}\left(n_{t}^{j}\right)^{1-\alpha}\right]^{\eta},
$$

where $y_{t}^{j}$ denotes output, $z^{j}$ denotes a sector-specific productivity, $\varepsilon_{t}^{j}$ denotes an idiosyncratic productivity shock drawn from the distribution $\mathbf{F}^{j}(\cdot), k_{t}^{j}$ and $n_{t}^{j}$ denote capital and labor inputs, respectively, $\alpha \in(0,1)$ denotes the capital share, and $\eta \in(0,1]$ is a span-of-control parameter.

The firm takes the real wage rate $W_{t}$ as given and chooses labor input $n_{t}^{j}$ to maximize the profit

$$
\pi_{t}^{j} \equiv \max _{n_{t}^{j}} \tilde{\tau}^{j}\left(z^{j} \varepsilon_{t}^{j} k_{t}^{j}\right)^{\alpha \eta}\left(n_{t}^{j}\right)^{(1-\alpha) \eta}-W_{t} n_{t}^{j},
$$

where $\tilde{\tau}^{j} \in(0,1)$ denotes the production subsidy for sector $j$.

The optimal labor demand function is given by

$$
n_{t}^{j}=\left(\frac{\eta(1-\alpha) \tilde{\tau}^{j}}{W_{t}}\right)^{\frac{1}{1-(1-\alpha) \eta}}\left(z^{j} \varepsilon_{t}^{j} k_{t}^{j}\right)^{\frac{\alpha \eta}{1-(1-\alpha) \eta}} .
$$

The maximum profit is given by

$$
\pi_{t}^{j}=\left(\tilde{\tau}^{j}\right)^{\frac{1}{1-\gamma}}(1-\gamma)\left(\frac{\gamma}{W_{t}}\right)^{\frac{\gamma}{1-\gamma}}\left(z^{j} \varepsilon_{t}^{j} k_{t}^{j}\right)^{\frac{\alpha \eta}{1-\gamma}} \equiv \tau^{j} R_{t}\left(z^{j} \varepsilon_{t}^{j} k_{t}^{j}\right)^{\tilde{\alpha}},
$$


where $\gamma \equiv(1-\alpha) \eta$ and $\tilde{\alpha} \equiv \frac{\alpha \eta}{1-\gamma}$. The term $\tau^{j} \equiv\left(\tilde{\tau}^{j}\right)^{\frac{1}{1-\gamma}}$ is the effective capital subsidy rate, and $R_{t} \equiv(1-\gamma)\left(\frac{\gamma}{W_{t}}\right)^{\frac{\gamma}{1-\gamma}}$ is the pre-subsidy rate of return on capital.

At the beginning of period $t$, a firm in sector $j$ has net worth $h_{t}^{j}$ carried over from period $t-1$ and it observes an idiosyncratic productivity shock $\varepsilon_{t}^{j} .8$ Given $\left(h_{t}^{j}, \varepsilon_{t}^{j}\right)$, the firm chooses capital input $k_{t}^{j}$, saving $s_{t}^{j}$, and loan $l_{t}^{j}$ to maximize its present value, subject to the flow-offunds constraint

$$
k_{t}^{j}=l_{t}^{j}+h_{t}^{j}-s_{t}^{j},
$$

the borrowing constraint

$$
0 \leq l_{t}^{j} \leq \theta^{j} h_{t}^{j}
$$

and the constraint on savings

$$
0 \leq s_{t}^{j} \leq h_{t}^{j} .
$$

In the borrowing constraint (39), the term $\theta^{j}$ is the loan-to-value ratio that determines the borrowing capacity for the firm.

The firm value is a discounted sum of current and future dividend flows, with the discount factor determined by the household's marginal utility. In particular, the firm value is given by

$$
V_{t}^{j}\left(h_{t}^{j}, \varepsilon_{t}^{j}\right)=d_{t}^{j}\left(h_{t}^{j}, \varepsilon_{t}^{j}\right)+\beta \frac{\Lambda_{t+1}}{\Lambda_{t}} \int V_{t+1}^{j}\left(h_{t+1}^{j}, \varepsilon_{t+1}^{j}\right) d \mathbf{F}^{j}\left(\varepsilon_{t+1}^{j}\right) .
$$

The dividend flow is given by

$$
d_{t}^{j}\left(h_{t}^{j}, \varepsilon_{t}^{j}\right) \equiv \tau^{j} R_{t}\left(z^{j} \varepsilon_{t}^{j} k_{t}^{j}\right)^{\tilde{\alpha}}+(1-\delta) k_{t}^{j}-\left(1+r_{l t}\right) l_{t}^{j}+\left(1+r_{d t}\right) s_{t}^{j}-h_{t+1}^{j},
$$

where $\delta \in(0,1)$ denotes the capital depreciation rate. The term $\beta \frac{\Lambda_{t+1}}{\Lambda_{t}}$ is the discount factor derived from the household's optimizing decisions (see Eq. (33)). The firm chooses $\left\{s_{t}^{j}, l_{t}^{j}, k_{t}^{j}, h_{t+1}^{j}\right\}$ to maximize $V_{t}^{j}\left(h_{t}^{j}, \varepsilon_{t}^{j}\right)$ subject to (38), (39), (40), and (42).

The following proposition characterizes the firm's optimizing decisions.

Proposition 6. Assume that the idiosyncratic shock is drawn from the interval $\left(\varepsilon_{\min }^{j}, \varepsilon_{\max }^{j}\right)$ according to the distribution function $\mathbf{F}^{j}(\varepsilon)$. Then, given $h_{t}^{j}$, the optimal allocations of saving $s_{t}^{j}$, borrowing $l_{t}^{j}$, and capital input $k_{t}^{j}$ are determined by

$$
\begin{aligned}
& s_{t}^{j}=\left\{\begin{array}{cc}
{\left[1-\left(\varepsilon_{t}^{j} / \underline{\varepsilon}_{t}^{j}\right)^{\frac{\tilde{\alpha}}{1-\alpha}}\right] h_{t}^{j}} & \text { if } \varepsilon_{\min }^{j} \leq \varepsilon_{t}^{j}<\underline{\varepsilon}_{t}^{j} \\
0 & \text { if } \underline{\varepsilon}_{t}^{j} \leq \varepsilon_{t}^{j}<\varepsilon_{\max }^{j}
\end{array},\right. \\
& l_{t}^{j}=\left\{\begin{array}{cc}
0 & \text { if } \varepsilon_{\min }^{j} \leq \varepsilon_{t}^{j}<\hat{\varepsilon}_{t}^{j} \\
{\left[\left(\varepsilon_{t}^{j} / \hat{\varepsilon}_{t}^{j}\right)^{\frac{\alpha}{1-\alpha}}-1\right] h_{t}^{j}} & \text { if } \hat{\varepsilon}_{t}^{j} \leq \varepsilon_{t}^{j}<\bar{\varepsilon}_{t}^{j} \\
\theta^{j} h_{t}^{j} & \text { if } \bar{\varepsilon}_{t}^{j} \leq \varepsilon_{t}^{j}<\varepsilon_{\max }^{j}
\end{array},\right.
\end{aligned}
$$

\footnotetext{
${ }^{8}$ This timing assumption follows Moll (2014) and simplifies our analysis significantly.
} 


$$
k_{t}^{j}=\left\{\begin{array}{cl}
\left(\varepsilon_{t}^{j} / \underline{\varepsilon}_{t}^{j}\right)^{\frac{\tilde{\alpha}}{1-\alpha}} h_{t}^{j} & \text { if } \varepsilon_{\min }^{j} \leq \varepsilon_{t}^{j}<\underline{\varepsilon}_{t}^{j} \\
h_{t}^{j} & \text { if } \underline{\varepsilon}_{t}^{j} \leq \varepsilon_{t}^{j}<\hat{\varepsilon}_{t}^{j} \\
\left(\varepsilon_{t}^{j} / \hat{\varepsilon}_{t}^{j}\right)^{\frac{\tilde{\alpha}}{1-\tilde{\alpha}}} h_{t}^{j} & \text { if } \hat{\varepsilon}_{t}^{j} \leq \varepsilon_{t}^{j}<\bar{\varepsilon}_{t}^{j} \\
\left(1+\theta^{j}\right) h_{t}^{j} & \text { if } \bar{\varepsilon}_{t}^{j} \leq \varepsilon_{t}^{j}<\varepsilon_{\max }^{j}
\end{array} .\right.
$$

The three cutoff points $\left\{\underline{\varepsilon}_{t}^{j}, \hat{\varepsilon}_{t}^{j}, \bar{\varepsilon}_{t}^{j}\right\}$ are defined as

$$
\begin{aligned}
\underline{\varepsilon}_{t}^{j} & =\left(h_{t}^{j}\right)^{\frac{1-\tilde{\alpha}}{\tilde{\alpha}}}\left[\frac{r_{d t}+\delta}{\tilde{\alpha} \tau^{j}\left(z^{j}\right)^{\tilde{\alpha}} R_{t}}\right]^{\frac{1}{\tilde{\alpha}}}, \\
\hat{\varepsilon}_{t}^{j} & =\left(h_{t}^{j}\right)^{\frac{1-\tilde{\alpha}}{\tilde{\alpha}}}\left[\frac{r_{l t}+\delta}{\tilde{\alpha} \tau^{j}\left(z^{j}\right)^{\tilde{\alpha}} R_{t}}\right]^{\frac{1}{\tilde{\alpha}}}, \\
\bar{\varepsilon}_{t}^{j} & =\left[\left(1+\theta^{j}\right) h_{t}^{j}\right]^{\frac{1-\tilde{\alpha}}{\tilde{\alpha}}}\left[\frac{r_{l t}+\delta}{\tilde{\alpha} \tau^{j}\left(z^{j}\right)^{\tilde{\alpha}} R_{t}}\right]^{\frac{1}{\tilde{\alpha}}} .
\end{aligned}
$$

The net worth $h_{t+1}^{j}$ can be solved from the envelope condition

$$
1=\beta \frac{\Lambda_{t+1}}{\Lambda_{t}} \int \frac{\partial V_{t+1}^{j}\left(h_{t+1}^{j}, \varepsilon_{t+1}^{j}\right)}{\partial h_{t+1}^{j}} d \mathbf{F}^{j}\left(\varepsilon_{t+1}^{j}\right)
$$

Proof. We prove the proposition in Appendix A.

Proposition 6 shows that, in the presence of the interest-rate wedge, a firm's optimizing decisions depend on the realized idiosyncratic productivity shocks $\varepsilon_{t}^{j}$. If productivity is sufficiently high (i.e., $\varepsilon_{t}^{j} \geq \bar{\varepsilon}_{t}^{j}$ ), then the firm will borrow up to the limit and finance investment using both its internal funds (net worth) and external debt. In the other extreme, if the productivity is sufficiently low (i.e., $\varepsilon_{t}^{j}<\underline{\varepsilon}_{t}^{j}$ ), then the firm will not borrow, and it will choose an optimal amount of saving, and to invest the remaining net worth. ${ }^{9}$

If the idiosyncratic productivity is between $\underline{\varepsilon}_{t}^{j}$ and $\bar{\varepsilon}_{t}^{j}$, then there are still two separate possibilities in the presence of the interest-rate wedge. In the case with a relatively high productivity $\varepsilon_{t}^{j}$ (specifically, if $\hat{\varepsilon}_{t}^{j} \leq \varepsilon_{t}^{j}<\bar{\varepsilon}_{t}^{j}$ ), then the firm will choose not to save, and it will finance investment with both internal funds and external debt, although the firm is not financially constrained. In the other case with a relatively low productivity (with $\underline{\varepsilon}_{t}^{j} \leq \varepsilon_{t}^{j}<\hat{\varepsilon}_{t}^{j}$ ), the firm will be neither a borrower nor a lender (i.e., in a financial autarky), and its investment is completely self-financed with internal funds.

The cutoff points $\underline{\varepsilon}_{t}^{j}, \hat{\varepsilon}_{t}^{j}$, and $\bar{\varepsilon}_{t}^{j}$ are functions of the net worth $h_{t}^{j}$, the interest rates $r_{d t}$ and $r_{l t}$, and other aggregate variables. Since the idiosyncratic shocks $\varepsilon_{t}^{j}$ follow an i.i.d. process

\footnotetext{
${ }^{9}$ Despite the low productivity shock, the firm still chooses to invest because, with decreasing returns, the marginal product of capital is high at low levels of capital input.
} 
and $h_{t}^{j}$ is independent of $\varepsilon_{t}^{j}$, the cutoff points are also independent of the idiosyncratic shocks. ${ }^{10}$

Eq. (49) shows that the ex ante marginal value of net worth is identical across firms, implying that the end-of-period net worth $h_{t+1}^{j}$ is also identical across firms. This result stems from the i.i.d. nature of the productivity shocks and the linearity of the dividend function in net worth (see Eq. (42)). ${ }^{11}$ However, the ex post marginal value of net worth $\frac{\partial V_{t+1}^{j}\left(h_{t+1}^{j}, \varepsilon_{t+1}^{j}\right)}{\partial h_{t+1}^{j}}$ varies across firms, depending on the realized productivity $\varepsilon_{t+1}^{j}$, as we show in Appendix A (see Eq. (A.58)). Eq. (49) implicitly determines the end-of-period net worth $h_{t+1}^{j}$ as a function of aggregate and sector-level variables.

III.1.3. Aggregation and Equilibrium. Define the aggregate effective units of capital as

$$
\tilde{K}_{t}^{j}=\int\left[z^{j} \varepsilon_{t}^{j} k_{t}^{j}\left(H_{t}^{j}, \varepsilon_{t}^{j}\right)\right]^{\tilde{\alpha}} d \mathbf{F}^{j}\left(\varepsilon_{t}^{j}\right)
$$

where we have used the equilibrium result that a firm's net worth is independent of the idiosyncratic shocks so that $h_{t}^{j}=H_{t}^{j}$, with $H_{t}^{j}$ denoting the aggregate net worth in sector $j$.

Denoting by $K_{t}^{j}$ the aggregate capital input used in sector $j=\{s, p\}$, we then have

$$
K_{t}^{j}=\int k_{t}^{j}\left(H_{t}^{j}, \varepsilon_{t}^{j}\right) d \mathbf{F}^{j}\left(\varepsilon_{t}^{j}\right) .
$$

A competitive equilibrium consists of allocations and prices such that (i) taking the prices as given, the allocations solve the optimizing problems of the household and the firms; and (ii) the prices clear the markets for capital, labor, loanable funds, and final goods.

Loanable funds market clearing implies that aggregate saving is equal to aggregate borrowing. In particular, we have

$$
\sum_{j=\{s, p\}} L_{t}^{j}=\sum_{j=\{s, p\}} S_{t}^{j}+B_{t},
$$

where

$$
\begin{aligned}
L_{t}^{j} & =\int l_{t}^{j}\left(H_{t}^{j}, \varepsilon_{t}^{j}\right) d \mathbf{F}^{j}\left(\varepsilon_{t}^{j}\right), \\
S_{t}^{j} & =\int s_{t}^{j}\left(H_{t}^{j}, \varepsilon_{t}^{j}\right) d \mathbf{F}^{j}\left(\varepsilon_{t}^{j}\right),
\end{aligned}
$$

and the household deposit $B_{t}=0$ under interest-rate controls.

\footnotetext{
${ }^{10}$ Proposition 6 implies that, in the limiting case with constant returns (i.e., with $\eta \rightarrow 1$ ), we have $\hat{\varepsilon}_{t}^{j} \rightarrow \bar{\varepsilon}_{t}^{j}$, so that all firms with $\varepsilon_{t}^{j} \geq \hat{\varepsilon}_{t}^{j}$ would be financially constrained and borrow up to the limit. Firms with sufficiently low productivity (i.e., with $\varepsilon_{t}^{j}<\underline{\varepsilon}_{t}^{j}$ ) would choose to save all net worth and not to invest.

${ }^{11} \mathrm{We}$ do not put any constraints on firms' dividend. As a result, firms with high productivity opt to distribute more dividends to the household and firms with low productivity may issue equity (i.e., negative dividends). Thus, the end-of-period net worth is identical across firms, despite their different productivity realizations $\varepsilon_{t}^{j}$.
} 
Capital market clearing implies that

$$
K_{t}=\sum_{j=\{s, p\}} H_{t}^{j}
$$

where aggregate capital stock $K_{t}$ is given by

$$
K_{t} \equiv \sum_{j=\{s, p\}} K_{t}^{j} .
$$

Labor market clearing implies that

$$
N_{t}^{s}+N_{t}^{p}=1
$$

where we have normalized aggregate labor supply to $N_{t}=1$.

Final goods market clearing implies that

$$
C_{t}=Y_{t}-K_{t+1}+(1-\delta) K_{t}
$$

where aggregate output $Y_{t}$ is given by

$$
Y_{t}=\sum_{j=\{s, p\}} Y_{t}^{j}
$$

and the sectoral output is

$$
Y_{t}^{j}=\left(\tilde{K}_{t}^{j}\right)^{1-(1-\alpha) \eta}\left(N_{t}^{j}\right)^{(1-\alpha) \eta} .
$$

Appendix B summarizes the full set of dynamic equilibrium conditions. Appendix C describes our approach to solving the steady-state equilibrium.

III.2. Calibration. The parameters to be calibrated include $\beta$, the subjective discount factor; $\alpha$, the capital income share; $\eta$, the degree of returns to scale; $\delta$, the capital depreciation rate; and $\phi$, the interest-rate wedge. We also need to calibrate the sector-specific parameters. For each sector $j \in\{s, p\}$, we need to calibrate the subsidy rate $\tilde{\tau}^{j}$, the loan-to-value ratio $\theta^{j}$, the sector-specific TFP $z^{j}$, and the parameters in the distributions $\mathbf{F}^{j}(\varepsilon)$ for the idiosyncratic shocks in each sector. The calibrated values are summarized in Table 1.

A period in our model corresponds to one year. We set the discount factor to $\beta=0.96$, implying a steady-state real interest rate of 4 percent. We calibrate the capital depreciation rate to 10 percent per year, so that $\delta=0.1$. We assume that the parameters in the production functions are identical for all firms, with the capital income share set to $\alpha=0.5$ based on the empirical evidence of Brandt et al. (2008) and Zhu (2012) for Chinese industries (see also Hsieh and Klenow (2009)). Following Midrigan and Xu (2014), we calibrate the span-ofcontrol parameter to $\eta=0.85$. We set the interest-rate wedge to $\phi=0.032$, in line with the average difference between the benchmark loan interest rate and the benchmark deposit rate in China for the period from 1996 to 2013, prior to the interest-rate liberalization reforms. 
We calibrate the sector-specific parameters using an unbalanced panel, with firm-level data from China's Annual Survey of Industries covering the period from 1998 to $2007{ }^{12}$

We normalize the POE wedge to $\tilde{\tau}^{p}=1$. We then calibrate the relative SOE wedge $\tilde{\tau}^{s}$ based on firms' optimizing decisions, using firm-level data in China's Annual Survey of Industries. Denote by $y_{m i t}^{j}$ and $n_{m i t}^{j}$ the output and the labor input of firm $i$ in industry $m$ and year $t$, with the ownership type $j \in\{s, p\}$. The firm's optimizing labor input decision (36) implies that

$$
\tilde{\tau}^{j}=\frac{W_{t} n_{m i t}^{j}}{(1-\alpha) \eta y_{m i t}^{j}} .
$$

Thus, given the calibrated values of $\alpha=0.5$ and $\eta=0.85$, we can construct an output wedge for each firm using the firm-level observations of wage payments and value added. After obtaining the firm-level output wedges, we compute the industry-level output wedges for each sector (SOE or POE) by taking the average of the output wedges across firms within the industry. Finally, we calculate the relative SOE wedge $\tilde{\tau}^{s}$ based on the ratios of SOE wedges to POE wedges, averaged across industries and across years from 1998 to 2007. This procedure yields a calibrated value of $\tilde{\tau}^{s}=1.44$.

To calibrate the loan-to-value (LTV) ratios $\theta^{s}$ and $\theta^{p}$, we first calculate the firm-level LTV measured by the ratio of the firm's long-term liabilities to fixed assets in China's Annual Survey of Industries data. We then calculate an industry-level LTV by taking the average of firm-level LTVs within the industry for each ownership type (SOE or POE) and in each year. These calculations lead to $\theta^{s}=0.504$ and $\theta^{p}=0.279$, corresponding to the average industry-level LTVs for SOEs and POEs, respectively, averaged across the years from 1998 to 2007.

To calibrate the sector-specific TFP levels, we normalize $z^{s}=1$ and calibrate the relative TFP of the POE sector $z^{p}$ using firm-level data in China's Annual Survey of Industries. The production function (34) implies that, regardless of the ownership type, the TFP for firm $i$ in industry $m$ and year $t$ is given by

$$
z_{m i t}=\left[\frac{y_{m i t}}{\left(k_{m i t}^{\alpha} n_{m i t}^{1-\alpha}\right)^{\eta}}\right]^{\frac{1}{\alpha \eta}}
$$

where $y_{m i t}$ denotes the output and $k_{m i t}$ and $n_{m i t}$ denote the capital and labor inputs. Since $\alpha=0.5$ and $\eta=0.85$ are identical for all firms, we can calculate the firm-level TFP $z_{m i t}$ directly based on Eq. (62) using data for value-added output, fixed assets (capital), and

\footnotetext{
${ }^{12}$ We provide a more detailed description about the data, the measurement, and the calibration approach in an online appendix available at https://www.frbsf.org/economic-research/files/ wp2017-15_appendix.pdf.
} 
employment for each firm, where we measure value-added output as the difference between a firm's total sales and payments on intermediate inputs. ${ }^{13}$

The TFP for a given industry $m$ is the average of TFPs across all firms within the industry given by

$$
\bar{z}_{m t}=\frac{1}{N_{m t}} \sum_{i=1}^{N_{m t}} z_{m i t},
$$

where $N_{m t}$ denotes the number of firms in industry $m$ and year $t$. Similarly, for each sector $j \in\{s, p\}$, the industry-level TFP is given by $\bar{z}_{m t}^{j}=\frac{1}{N_{m t}^{j}} \sum_{i=1}^{N_{m t}^{j}} \mathbf{1}_{(j)} \times z_{m i t}$, where $\mathbf{1}_{(j)}$ is a dummy variable that equals one if firm $i$ in industry $m$ has ownership type $j$, and zero otherwise. We take the average of sector $j$ 's TFP across industries within the sector and calculate the relative TFP of the POE sector $\frac{z_{t}^{p}}{z_{t}^{s}}$ for each year. Averaging across time (from 1998 to 2007), we obtain the calibrated value of $z^{s}=1.92$, which is the relative TFP of the POE sector at the aggregate level. This calibration implies that POEs are on average 92 percent more productive than SOEs, in line with the estimated TFP gaps between POEs and SOEs reported in the literature. ${ }^{14}$

The firm-level TFPs calculated based on Eq. (62) also help us to calibrate the parameters in the idiosyncratic shock distributions $\mathbf{F}^{s}(\varepsilon)$ and $\mathbf{F}^{p}(\varepsilon)$. Assume that the idiosyncratic shocks in sector $j \in\{s, p\}$ follow a log-normal process, with the mean normalized to one and the standard deviation denoted by $\sigma^{j}$. We calibrate $\sigma^{s}$ and $\sigma^{p}$ in two steps. First, the firm-level TFP distribution implies that $\frac{\sigma^{p}}{\sigma^{s}}=1.23$. Second, we calibrate the level of $\sigma^{s}$ to match the share of borrowers in the SOE sector. We define a borrower as a firm that has a year-over-year increase in its LTV of at least 1 percentage point. With this definition, the average share of borrowers in the SOE sector is about 39 percent in our sample period from 1998 to 2007 . We calibrate $\sigma^{s}=0.375$ so that the model implies that the share of SOE borrowers in the initial steady state is 39 percent, as in the data. Given the calibrated value of $\sigma^{s}$, we obtain $\sigma^{p}=1.23 \sigma^{s}=0.461 .^{15}$

\footnotetext{
${ }^{13}$ We calculate the firm-level TFP based on the production function. Unlike Hsieh and Klenow (2009), we do not need information about firm-level prices and quantities or the output wedges $\tau^{s}$ and $\tau^{p}$, because our calculation does not involve firms' optimizing decisions. However, our approach does require the assumption that the production function parameters $\alpha$ and $\eta$ are identical for all firms, as in Midrigan and Xu (2014).

${ }^{14}$ For example, Brandt et al. (2008) estimate that the TFP gap between POE and SOE is about 1.8 over the period from 1998 to 2004. Brandt and Zhu (2010) report an estimated gap of 2.3 for 2004.

${ }^{15}$ Since the idiosyncratic productivity shocks are i.i.d. in our model, we cannot directly calibrate the levels of both $\sigma^{s}$ and $\sigma^{p}$ to match the observed productivity dispersion across firms in the two sectors. Instead, we calibrate the ratio $\frac{\sigma^{p}}{\sigma^{s}}$ to match the observed relative dispersion of productivities in the POE sector, and then we pin down the level of $\sigma^{s}$ in the model by matching the observed share of borrowers in the SOE sector in the data.
} 
III.3. Transition dynamics. We now discuss the dynamic effects of interest-rate liberalization. The economy starts with the initial steady state with interest-rate controls (i.e., $\phi=0.032$ ). Suppose that, in period 2, the interest-rate wedge is permanently removed (i.e., $\phi=0)$. Over time, the economy will converge to a new steady state without interest-rate controls. We study the transition dynamics following the the interest-rate liberalization.

Figure 3 shows the transition dynamics of the interest rates, the share of capital held by the SOE sector, and the levels of sector-specific TFP, aggregate TFP, aggregate output, the real wage rate, and aggregation consumption. Consistent with the analytical results stated in Proposition 4, the loan interest rate declines, the deposit rate rises, and the two rates collapse into one following the liberalization reform. Under government subsidies, SOEs have an incentive to expand their scale, and they also have easier access to credit than POEs. Thus, capital flows from POEs to SOEs, leading to an increase in the share of capital held by SOE firms. Since SOEs are on average less productive than POEs, this reallocation of capital to the SOE sector exacerbates misallocation and, all else being equal, reduces aggregate TFP. On the other hand, the liberalization reform moves capital from lowproductivity firms to high-productivity firms within each sector and thus it raises measured TFP in both sectors. This within-sector improvement in capital allocation counteracts the between-sector deterioration in allocations, rendering the net effects of the liberalization reform on aggregate TFP ambiguous.

Under our calibrated parameters, the liberalization policy leads to a small short-run decline in aggregate TFP, which then rises to a permanently higher level in the new steady state. The short-run decline in aggregate TFP contributes to a small initial drop in aggregate output. Over time, however, output rises above the initial steady state and reaches a permanently higher new steady-state level. The higher aggregate output in the long run reflects the effects of both a higher level of aggregate TFP and an increase in aggregate capital stock, since the liberalization reform encourages savings through raising the deposit interest rate. ${ }^{16}$

Interest-rate liberalization also raises the real wage rate. The increases in wages reallocate resources to the more productive POEs, partly reversing the initial flows of capital to the SOEs. Although the liberalization policy has a small initial impact on aggregate output, it reduces consumption persistently, reflecting the increases in SOE over-investment, which is exacerbated by the capital reallocation across the two sectors.

The liberalization policy in our model has welfare implications that are different from the standard model. In the standard model, interest-rate liberalization raises aggregate TFP

\footnotetext{
${ }^{16}$ Under our calibrated parameters, TFP in each sector as well as aggregate TFP reach their new steady state levels quickly. This is not a general result, but specific to our calibration. In general, the TFP levels should depend (in part) on the slow-moving net worth and can be slow-moving as well.
} 
and improves welfare unambiguously (Moll, 2014). In our two-sector model, however, distorted SOE incentives create a tradeoff between within-sector and between-sector allocation efficiencies, rendering the welfare implications of interest-rate liberalization ambiguous.

Figure 4 shows the welfare losses following a removal of the interest-rate wedge of a given size (indicated on the horizontal axis) during the transition process. If the welfare change is negative, then removing the interest-rate wedge would reduce welfare. For example, if the wedge is initially at $\phi=0.01$, then removing the wedge would incur a modest welfare loss equivalent to 0.3 percent of steady-state consumption per year. If the initial wedge is at the calibrated value of $\phi=0.032$, then removing that wedge results in a welfare loss of 0.32 percent of steady-state consumption, consistent with the SOE over-investment and the resulting short-run declines in aggregate consumption. The figure also reveals that the welfare loss is not a monotone function of the initial interest-rate wedge. In this second-best environment, the tradeoff for interest-rate liberalization implies that there exists an optimal interest rate wedge (at around 0.02 ) that maximizes social welfare.

III.4. Counterfactual experiments. The nonstandard results about aggregate TFP and social welfare in our model stem from two key sources of distortions: SOE subsidies and preferential access to credit. To highlight the role played by each of these two forms of distortions, we now examine two counterfactual experiments, one with no SOE subsidies, and the other with equal credit access for all firms in the two sectors.

III.4.1. Eliminating SOE subsidies. In our calibrated model, SOEs receive favorable government subsidies for production. We now examine the transition dynamics following an interest-rate liberalization in a counterfactual economy with the SOE subsidy eliminated (i.e., $\tilde{\tau}^{s}=\tilde{\tau}^{p}=1$ ). In this counterfactual, we maintain the calibrated values of $\theta^{s}$ and $\theta^{p}$, such that SOEs still have easier access to credit than POEs.

The left column in Figure 5 shows the transition dynamics in this counterfactual. Although SOEs do not receive subsidies, they still face a higher borrowing limit than POEs. Thus, following the interest-rate liberalization, capital still flows from POEs to SOEs, as in the benchmark model. However, without SOE subsidies, the steady-state size of the SOE sector shrinks, mitigating the adverse impact of the between-sector misallocations on aggregate TFP and output. Under our calibrated parameters (and with $\tilde{\tau}^{s}=1$ ), the improvements in capital allocations within each sector dominate the between-sector misallocation effects, such that aggregate TFP rises permanently after the reform. Accordingly, aggregate output rises along the transition path until reaching a permanently higher new steady-state level.

The left panel in Figure 6 shows that, in this counterfactual with no SOE subsidies, interest-rate liberalization improves social welfare for all initial values of the interest-rate 
wedge. This welfare outcome stands in contrast to that in the benchmark model, in which eliminating the interest-rate wedge can lead to welfare losses for a range of values of the initial wedge.

III.4.2. Equal credit access. In our benchmark model, the loan-to-value ratio for SOEs is about 2.5 times as large as that for POEs $\left(\theta^{s}=0.504\right.$ and $\left.\theta^{p}=0.279\right)$. The superior access to credit for SOE firms contributed to misallocations of capital across sectors. We now consider a counterfactual case with equal credit access for the two types of firms (i.e., with $\left.\theta^{p}=\theta^{s}=0.504\right)$, holding all the other parameters unchanged at their calibrated values, including SOE subsidies $\left(\tilde{\tau}^{s}=1.44\right)$.

The right column in Figure 5 shows the transition dynamics following an interest-rate liberalization in this counterfactual case. Since SOEs continue to receive subsidies, the liberalization policy still reallocates capital from POEs to SOEs, and thus exacerbates misallocations. However, the relative size of the SOE sector and the magnitude of increases in the SOE capital share are both smaller than those in the benchmark model. At the same time, POEs have improved credit access relative to the benchmark model, so they are better able to expand production following the liberalization. The liberalization policy raises aggregate TFP permanently, reflecting that the within-sector improvement in allocations dominates the between-sector misallocations. Consequently, aggregate output rises along the transition path, until it reaches a permanently higher new steady-state level.

Granting equal credit access to POEs also implies that removing the interest-rate wedge is more likely to improve social welfare than in the benchmark model. As shown in the right panel of Figure 6, the case with equal credit access features a smaller range of values of the initial interest-rate wedge for which liberalization reduces welfare.

Comparing the welfare effects between the two counterfactuals (i.e., the two panels in Figure 6) reveals that SOE subsidies are a more important source of misallocations and welfare losses following interest-rate liberalization than unequal credit access. In the case with no SOE subsidies, removing the interest-rate wedge leads to unambiguous welfare gains (see the left panel of the figure), despite the SOEs' superior credit access. In the other case with equal credit access but with SOE subsidies, there is a range of values of the initial interest-rate wedge for which removing the wedge reduces welfare (see the right panel of the figure). ${ }^{17}$ To

\footnotetext{
${ }^{17} \mathrm{We}$ have also considered a counterfactual model with a single sector, corresponding to the standard model in the literature. We calibrate the parameters $\theta, \sigma$, and $z$ by taking the averages of the sector-specific calibrations in our benchmark model and find that interest-rate liberalization in this onesector model unambiguously raises aggregate TFP and improves welfare, confirming the findings by Moll (2014). For details, see the online appendix at https://www.frbsf.org/economic-research/ files/wp2017-15_appendix.pdf.
} 
mitigate misallocations and avoid welfare losses, interest-rate liberalization reforms should be implemented along with other reforms that alleviate distorted SOE incentives.

\section{EMPIRICAL EVIDENCE}

In our model, the government subsidizes SOE production and grants them preferential credit access. Our model implies that, without removing the SOE subsidies and preferential credit treatments, pursuing interest-rate liberalization reforms can exacerbate capital misallocations by moving capital from POEs to less productive SOEs. We now provide some empirical evidence that supports the model's mechanism.

Aggregate data are not very informative for identifying the effects of interest-rate liberalization on capital reallocations between SOEs and POEs. The Chinese government has maintained tight controls over the loan interest rate until 2013 and the deposit rate until 2015. Even after 2015, interest-rate liberalization has been a gradual and ongoing process, with slow adjustments of the deposit and loan interest rates toward market-determined levels (see Figure 1). At the same time, many other things have happened in the Chinese economy that may confound the effects of interest-rate liberalization. For example, the People's Bank of China relaxed pegs of renminbi to the dollar in 2015, and later switched to pegging a basket of currencies instead of the dollar. The government has also tightened regulations over corporate leverages and shadow banking activities in 2016 and 2017. Since 2018, trade tensions between China and the United States have escalated. These developments also drive changes in the allocations of capital, presenting a challenge to isolate the effects of interest-rate liberalization using aggregate time-series data.

It is more promising to use disaggregated data to evaluate our model's mechanism. For our purpose, we use China's Annual Survey of Industries data - the same data set that we have used for calibrating our dynamic model - to examine how changes in the interest-rate wedge are related to industry-level productivity, and how the presence of capital misallocations can affect that relation. Our sample covers the years from 1998 to 2007.

We first construct a distortion dummy, denoted by $D_{m t}$, for each industry $m$ and each year $t$. Our model implies that, absent government subsidies and preferential credit policy, a borrowing firm should always have higher productivity than an autarkic firm (i.e, a firm that is neither a borrower nor a lender). We measure a firm's productivity using the firmlevel TFP that we constructed (see Section III.2). We define the dummy variable $D_{m t} \equiv$ $\mathbf{1}\left(z_{m t}^{\text {autarky }, 1 \%} \geq z_{m t}^{\text {borrow }, 1 \%}\right)$, which equals one if the TFP of the bottom 1 percentile of firms at financial autarky (denoted by $z_{m t}^{\text {autarky, } 1 \%}$ ) exceeds that of the bottom 1 percentile of firms that are borrowers (denoted by $z_{m t}^{\text {borrow, } 1 \%}$ ). Otherwise, $D_{m t}=0$. We classify a firm in a given industry as an autarkic firm if its leverage ratio has remained roughly unchanged from 
the previous year. A firm is a borrower if its leverage has increased by more than a certain threshold. We measure firm leverage by the ratio of its long-term liabilities to total fixed assets. In our baseline regression, a firm is in financial autarky if the absolute year-over-year change in its leverage is less than 1 percent. We consider a firm a borrower if its leverage has increased by more than 1 percent from the previous year. To check the robustness of our results, we also consider alternative thresholds for borrowers, whose leverage increased by at least 2 percent or 5 percent from the previous year. ${ }^{18}$

Using an unbalanced panel with 476 industries over the years 1998-2007, we estimate the empirical specification

$$
\Delta Y_{m t}=\beta_{0}+\beta_{1} D_{m t}+\beta_{2} \Delta \phi_{t}+\beta_{3} D_{m t} \times \Delta \phi_{t}+\beta_{4} X_{m t}+\delta_{m}+\rho \Delta Y_{m, t-1}+\varepsilon_{m t},
$$

where $\Delta Y_{m t}$ denotes the year-over-year growth rate of the average labor productivity in industry $m$ and year $t$; $X_{m t}$ denotes a set of control variables, including the industry's average leverage $\left(L T V_{m t}\right)$ and the growth rates of average fixed assets $\left(\Delta K_{m t}\right)$ and employment $\left(\Delta L_{m t}\right) ; \Delta \phi_{t}$ denotes the year-over-year changes in the interest-rate wedge (i.e, the differences between the benchmark loan rates and the benchmark deposit rates); and $\delta_{m}$ captures the industry fixed effects. The term $\varepsilon_{m t}$ denotes the regression residuals.

Our theory implies that, all else being equal, interest-rate liberalization (i.e., a reduction in the interest-rate wedge) should raise labor productivity. Thus, we should expect $\beta_{2}<0$ in our empirical specification (64). However, in an industry with distorted allocations (i.e., $D_{m t}=1$ ), interest-rate liberalization can lower the industry's productivity by moving capital to firms that are less productive but more favored by government policy. Thus, we should expect $\beta_{3}>0$.

We estimate the dynamic panel model in Eq. (64) using the Arellano and Bond (1991) estimator. $^{19}$ Table 2 shows the estimation results. Column (1) shows the baseline case, in which a borrower is defined as a firm whose leverage increased at least 1 percent from the previous year. Consistent with our model's mechanism, the point estimate of $\beta_{2}$ is negative $(-0.723)$ and significant (with a p-value less than 5 percent). The estimated value of $\beta_{2}$

\footnotetext{
${ }^{18}$ In our sample, an SOE dominant industry (i.e., an industry with SOE employment share exceeding $50 \%$ ) is more likely to have distorted allocations under our measure of distortions. In particular, an estimated Probit model shows that, controlling for industry fixed effects, an SOE dominant industry is $53 \%$ more likely to have distorted allocations (i.e., $D_{m t}=1$ ).

${ }^{19}$ To estimate the dynamic panel specification, we use the two-step system GMM estimator with smallsample robust corrections. We implement the estimation in STATA using the command xtabond. We use the lagged dependent variable and lagged control variables as GMM-type instruments. Two tests support our model specification: the null hypothesis of second-order autocorrelations is rejected, and the heteroskedasticity-consistent Hansen's J-tests fail to reject the validity of our instrument set.
} 
suggests that, holding all else equal, reducing the interest-rate wedge by one percentage point would raise the average productivity growth by 0.72 percentage point. The estimate for $\beta_{3}$ is positive (0.921) and also significant (with a p-value less than 5 percent). Thus, if an industry has distorted allocations $\left(D_{m t}=1\right)$, then reducing the interest-rate wedge by 1 percentage point would lower the industry's labor productivity by 0.92 percentage point. The net effects of interest-rate liberalization on industry-level productivity are slightly negative $(0.921-0.723=0.18)$ but statistically insignificant. ${ }^{20}$

The empirical evidence is robust to alternative definitions of the borrowers. In particular, Columns (2) and (3) in Table 2 show the estimation results when we define a borrower as a firm whose leverage increased at least 2 percent and 5 percent, respectively, from the previous year. The estimated $\beta_{2}$ and $\beta_{3}$ are similar to those in the baseline case shown in Column (1). ${ }^{21}$

The evidence is also robust to several alternative measures of the distortion dummy $D_{m t}$. In one experiment, we use alternative thresholds in our measure of the distortion dummy. In particular, we compare the $x \%$ tails of TFP between borrowing firms and autarkic firms, with $x \in\{2.5,5,10\}$ instead of the $1 \%$ tails of TFP used for the baseline regression. In a second experiment, we measure the distortion by the dispersion of the marginal products of capital across firms within a industry. In both experiments, we have obtained qualitatively similar results as those in the baseline. ${ }^{22}$

These empirical results confirm that, in the presence of distorted allocations (i.e., with $D_{m t}=1$ ), interest-rate liberalization can significantly reduce an industry's productivity, lending credence to our model's mechanism.

\footnotetext{
${ }^{20}$ We have considered an alternative panel regression by including time fixed effects, in which case the effects of $\Delta \phi_{t}$ cannot be separately identified, but we can still identify the effects of the interaction term $D_{m t} \times \Delta \phi_{t}$. In this regression, we obtain a statistically significant point estimate of 1.278 for the coefficient on the interaction term (with a standard error of 0.50). This result suggests that, in an industry with distorted allocations, a 1 percentage point reduction in the interest-rate wedge reduces the industry's productivity growth by 1.3 percentage points, a magnitude that is slightly larger than that in the baseline regression model. We have also obtained qualitatively similar results when we estimate a static panel model without the lagged dependent variable in Eq. (64).

${ }^{21}$ To take into account the possibility that some firms might increase leverage to cover operating losses, we considered an alternative measure of borrowers by focusing on borrowing firms with positive profits. We obtained similar results.

${ }^{22}$ We report the details of these robustness results in the online appendix at https://www. frbsf. org/economic-research/files/wp2017-15_appendix.pdf.
} 


\section{Related Literature}

Our paper contributes to the literature on misallocations and financial frictions. Existing studies have documented evidence that misallocations of resources help explain a large part of cross-country differences in productivity and income (Restuccia and Rogerson, 2008; Hsieh and Klenow, 2009; Buera et al., 2011; Bartelsman et al., 2013) . Financial frictions can reduce TFP by distorting firm entry and technology adoption decisions (Cole et al., 2016) or by generating dispersions in capital returns across firms and thus causing misallocations (Banerjee and Duflo, 2005; Jeong and Townsend, 2007; Banerjee and Moll, 2010; Liu and Wang, 2014; Moll, 2014). Midrigan and Xu (2014) present establishment-level evidence that financial frictions cause efficiency losses mainly through depressing firm entry and technology adoptions. $^{23}$

The literature has also studied the impact of financial liberalization on resource allocations. Song et al. (2011) construct a two-sector growth model with less-productive SOEs and more-productive but financially constrained POEs. They show that the credit market imperfections provide a key mechanism for understanding China's economic transition. Gao et al. (2017) study the effects of China's 2009 deregulation of bank entries. They find that, after the deregulation, most loans originated from new entrant banks went to SOEs, which had explicit or implicit government guarantees and were thus considered "safe" borrowers. The deregulation also led to increased competition between new and incumbent banks, raising the overall quality of all loans, with significantly longer maturity and lower delinquency rates. Increased bank competition following the 2009 banking deregulation also led to improvements in the efficiency of firms that borrowed from banks, with private firms benefiting more than SOEs. Thus, consistent with our theory, the banking deregulation had ambiguous net effects on allocative efficiency. Liu et al. (2019) examine the potential impact of capital account liberalization in China in the presence of domestic financial repression. ${ }^{24}$ Reis (2013) shows that, because of financial frictions, capital inflows to Portugal in the 2000s may have been misallocated to inefficient firms in the nontradable sector at the expense of more-productive firms in the tradable sector. Gopinath et al. (2017) present a model with heterogeneous firms and size-dependent financial frictions. They show that the decline in the real interest rate during the euro convergence process in the 1990s has led to increased dispersions in capital returns and a lower TFP in Spain, Portugal, and Italy, because capital inflows are misallocated toward firms that have higher net worth but are not necessarily

\footnotetext{
${ }^{23}$ Other studies on this topic include Brandt et al. (2013), Gilchrist et al. (2013), Caggese and Cuñat (2013), and Buera et al. (2013). See Restuccia and Rogerson (2013, 2017) for surveys of this literature.

${ }^{24}$ Chang et al. (2015b) build a DSGE model of China to examine the implications of China's capital controls for its domestic monetary policy when external shocks raise the cost of sterilization.
} 
more productive. Bleck and Liu (2018) study a two-sector model with collateral constraints, with different degrees of financial frictions across sectors. They show that excessive liquidity injection can overheat the sector with lower friction, crowding liquidity out of the sector with higher friction. Chang et al. (2019) study the role of reserve requirements for China's macroeconomic stabilization in a two-sector DSGE model with SOEs and POEs and segmented credit markets. In their model, banks lend to inefficient SOEs at low interest rates because of the low risks under government guarantees. However, banks charge a default premium on off-balance-sheet loans to POEs, even though their productivity is higher than SOEs. An increase in reserve requirements acts as a tax on SOE loans, reallocating capital to the more efficient POEs from SOEs, improving aggregate productivity while also raising the social costs for bailing out SOEs. In a similar spirit, Wang et al. (2016) argue that, since inefficient SOEs enjoy easy access to cheap bank credit, shadow banking loans provide productive POEs with urgently needed credit and thus helps improve allocative efficiency. Chang et al. (2015a) build a two-sector model that focuses on credit reallocations between heavy and light sectors. Their calibrated model is able to replicate the observed trends and cycles of China's aggregate economy.

Our study has a different focus. We examine the implications of interest-rate liberalization for aggregate productivity and welfare in a two-sector general equilibrium model that incorporates firm-level heterogeneity, credit constraints, and asymmetric policy treatments across sectors. In this second-best environment, we show that interest-rate liberalization can have ambiguous effects on aggregate TFP and welfare because it improves within-sector capital allocation at the expense of between-sector misallocations.

\section{Conclusion}

We have studied implications of interest-rate liberalization for capital allocation, aggregate productivity, and social welfare in a two-sector general equilibrium model with Chinese characteristics. The model features heterogeneous productivity, credit constraints, and government policies that favor SOEs over more efficient POEs. In this second-best environment, lifting interest-rate controls can improve capital allocation efficiency within each sector but exacerbate misallocations across sectors. Since SOEs have easier access to credit and an incentive to expand their scale, the extra saving induced by the reform disproportionately flows to the SOE sector. The overall effects of interest-rate liberalization on aggregate TFP and welfare depend on parameters. With calibrated parameters, the model suggests that interest-rate liberalization can modestly reduce aggregate TFP along the transition path, but boosts it in the long run. The liberalization reform has an ambiguous welfare effect. It can improve or reduce social welfare, depending the size of the initial interest-rate wedge. 
With our calibrated wedge, the reform leads to a modest welfare loss. We further show that, if other structural reforms are simultaneously implemented to mitigate distorted SOE incentives, interest-rate liberalization can improve welfare. 
Table 1. Calibrated Parameter Values

\begin{tabular}{llc}
\hline \hline$\beta$ & Discounting factor & 0.96 \\
$\alpha$ & Capital share & 0.5 \\
$\eta$ & Returns to scale & 0.85 \\
$\delta$ & Capital depreciation rate & 0.1 \\
$\phi$ & Interest-rate wedge & 0.032 \\
$\theta^{s}$ & SOE borrowing constraint & 0.504 \\
$\theta^{p}$ & POE borrowing constraint & 0.279 \\
$z^{s}$ & SOE-specific TFP (normalized) & 1 \\
$z^{p}$ & POE-specific TFP & 1.92 \\
$\sigma^{s}$ & SOE productivity dispersion & 0.375 \\
$\sigma^{p}$ & POE productivity dispersion & 0.461 \\
$\tau^{s}$ & SOE output wedge & 1.44 \\
$\tau^{p}$ & POE output wedge (normalized) & 1 \\
\hline
\end{tabular}


TABLE 2. The impact of changes in the interest-rate wedge on labor productivity

\begin{tabular}{lccc}
\hline \hline$\Delta Y_{m t}$ & $(1)$ & $(2)$ & $(3)$ \\
\hline$\Delta \phi_{t}$ & $-0.723^{* *}$ & $-0.753^{* *}$ & $-0.765^{* *}$ \\
& $(0.299)$ & $(0.313)$ & $(0.308)$ \\
$D_{m t} \times \Delta \phi_{t}$ & $0.921^{* *}$ & $0.970^{* *}$ & $0.979^{* *}$ \\
& $(0.456)$ & $(0.486)$ & $(0.491)$ \\
$D_{m t}$ & -0.020 & -0.019 & -0.027 \\
& $(0.053)$ & $(0.049)$ & $(0.052)$ \\
$\Delta K_{m t}$ & $0.176^{*}$ & $0.178^{* *}$ & $0.211^{* *}$ \\
& $(-0.090)$ & $(0.090)$ & $(0.090)$ \\
$\Delta L_{m t}$ & -0.077 & -0.087 & -0.075 \\
& $(-0.108)$ & $(0.108)$ & $(0.127)$ \\
$L T V_{m t}$ & -0.037 & -0.038 & -0.046 \\
& $(-0.028)$ & $(0.029)$ & $(0.032)$ \\
$\Delta Y_{m t-1}$ & -0.057 & -0.055 & -0.022 \\
& $(-0.085)$ & $(0.086)$ & $(0.062)$ \\
\hline Number of Observations & 2,806 & 2,806 & 2805 \\
Number of Industries & 476 & 476 & 476 \\
Hansen test (p value) & 0.217 & 0.161 & 0.170 \\
AB test AR(1) (p value) & 0.000 & 0.000 & 0.000 \\
AB test AR(2) (p value) & 0.432 & 0.404 & 0.641 \\
\hline
\end{tabular}

Notes: This table reports the estimated impact of changes in the interest-rate wedge (denoted by $\Delta \phi_{t}$ ) on industry-level labor productivity using data from China's Annual Survey of Industries. The empirical model is specified in Eq. (64) in the text. We estimate the dynamic panel model using the Arellano and Bond (1991) approach, with the instrumental variables including the control variables and lags of the dependent variable. The control variables include the industry's average leverage $\left(L T V_{m t}\right)$ and the year-over-year growth rates of average fixed assets $\left(\Delta K_{m t}\right)$ and employment $\left(\Delta L_{m t}\right)$. The variable $D_{m t}$ is a distortion dummy, which equals one if the average TFP of the bottom percentile of borrowing firms is lower than that of the bottom percentile of autarkic firms. An autarkic firm has a year-over-year change in its loan-to-value ratio of less than 1 percent (in absolute value). A borrowing firm has its loanto-value ratio increased by at least $x$ percent from the previous year, where we consider $x \in\{1,2,5\}$, corresponding to the results shown in Columns (1), (2), and (3). The numbers in the parentheses are robust standard errors. The statistical significance levels are denoted by $*(\mathrm{p}<0.1),{ }^{* *}(\mathrm{p}<0.05)$, and $* * *(\mathrm{p}<0.01)$. 


\section{China deposit and lending rates}

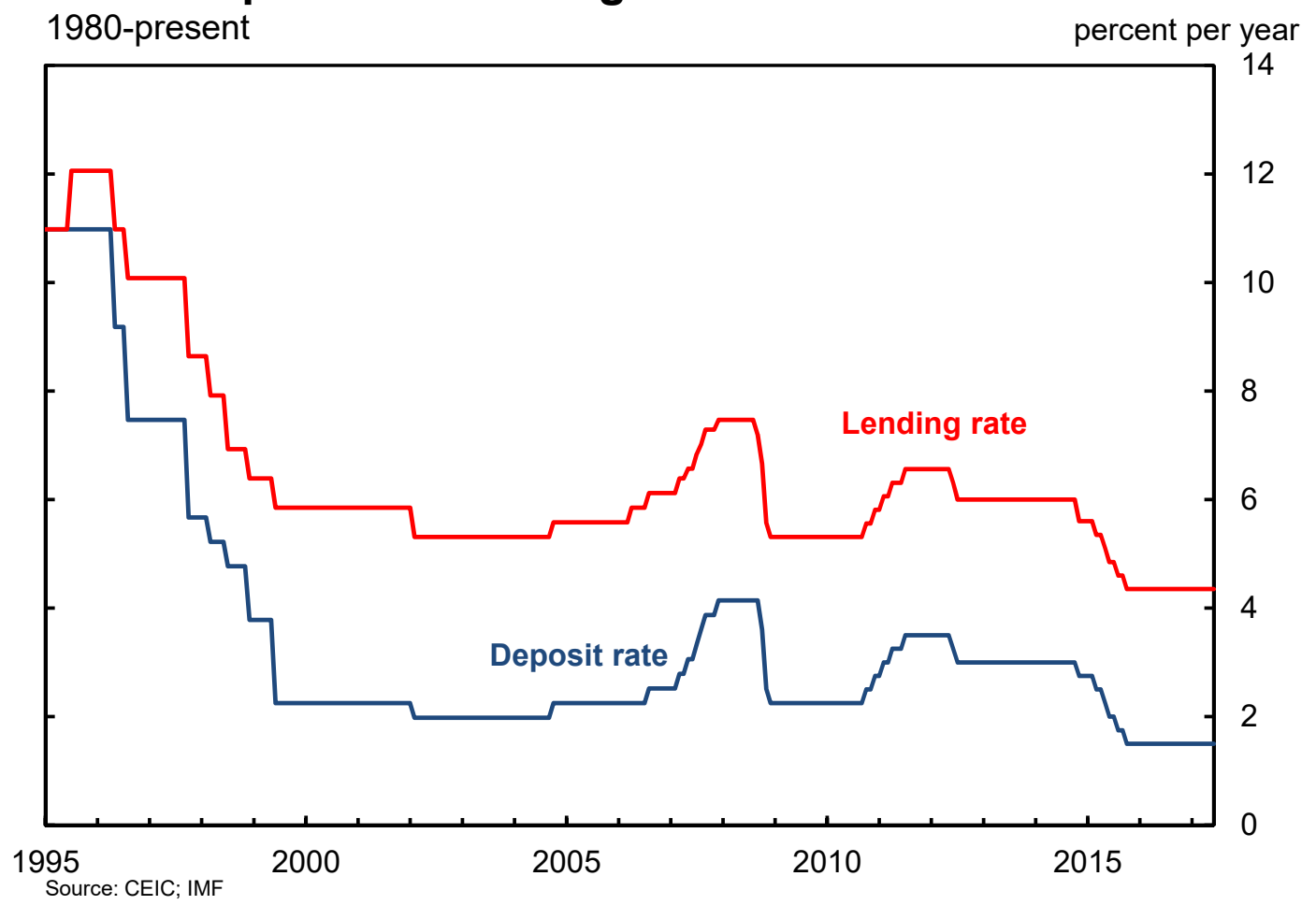

Figure 1. Time series of China's one-year benchmark deposit interest rate and one-year benchmark lending interest rate. Source: CEIC and IMF. 


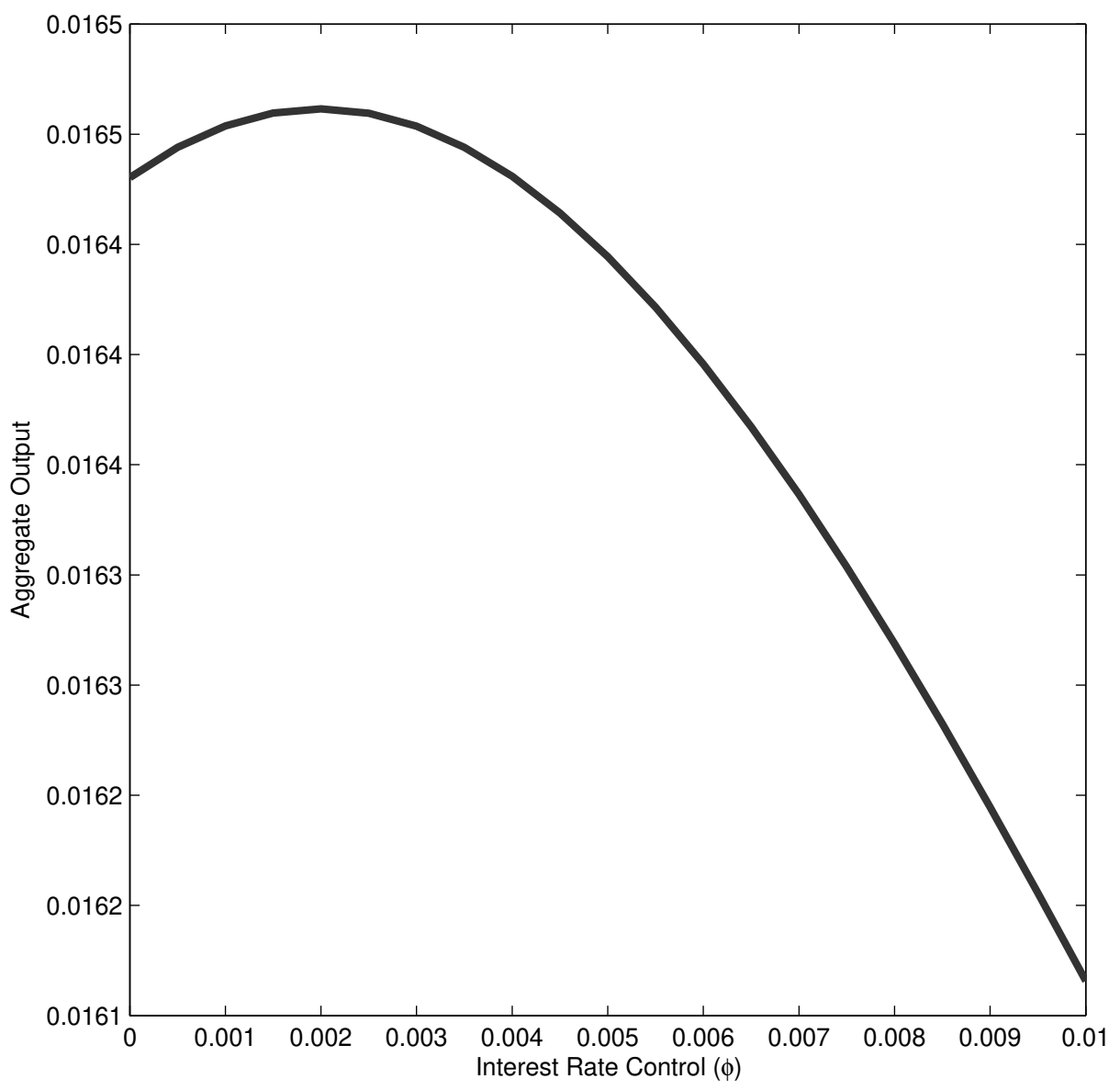

Figure 2. Aggregate output and the interest-rate wedge in the static model. 

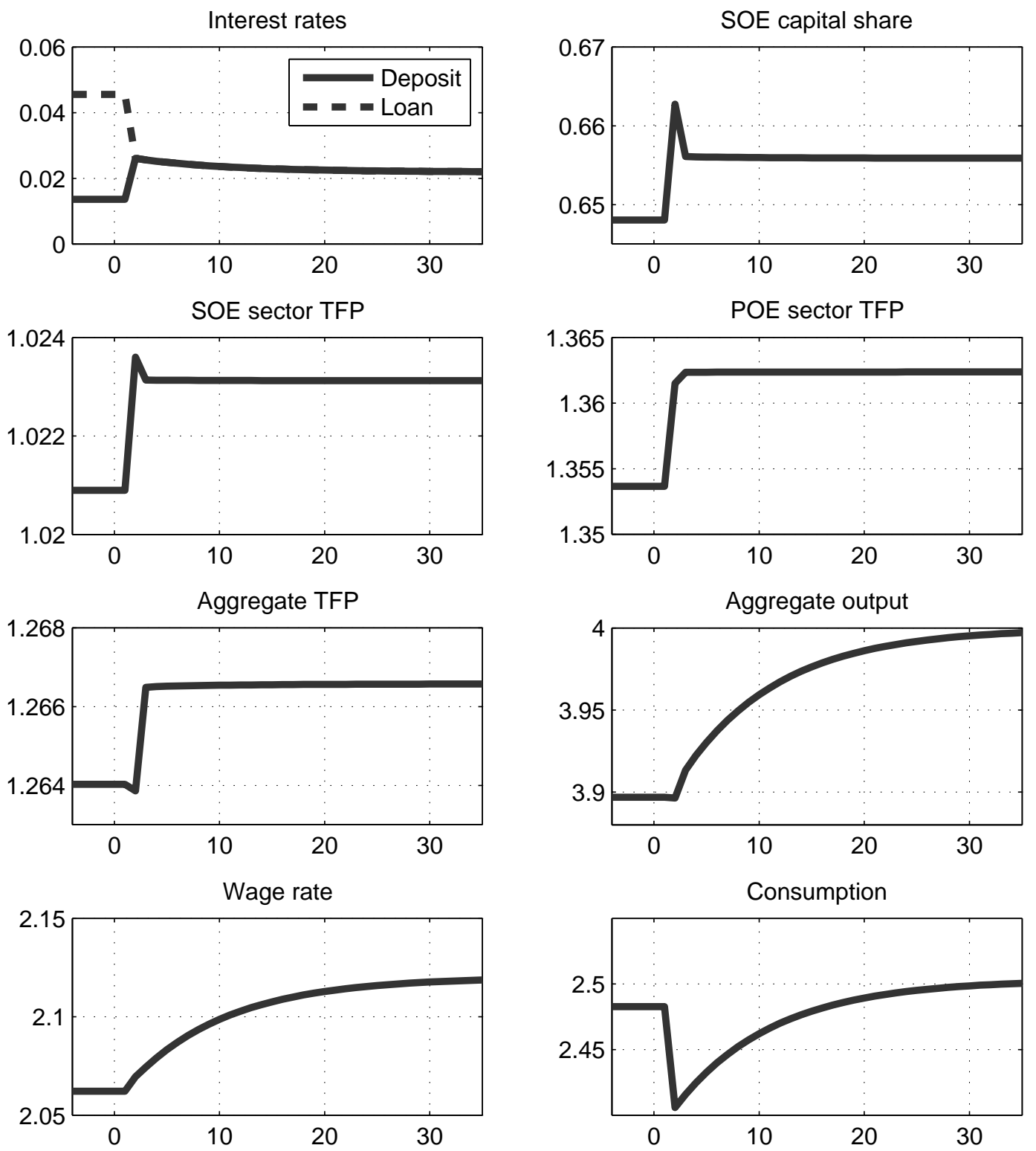

Figure 3. Transition dynamics following interest-rate liberalization in the benchmark model. 


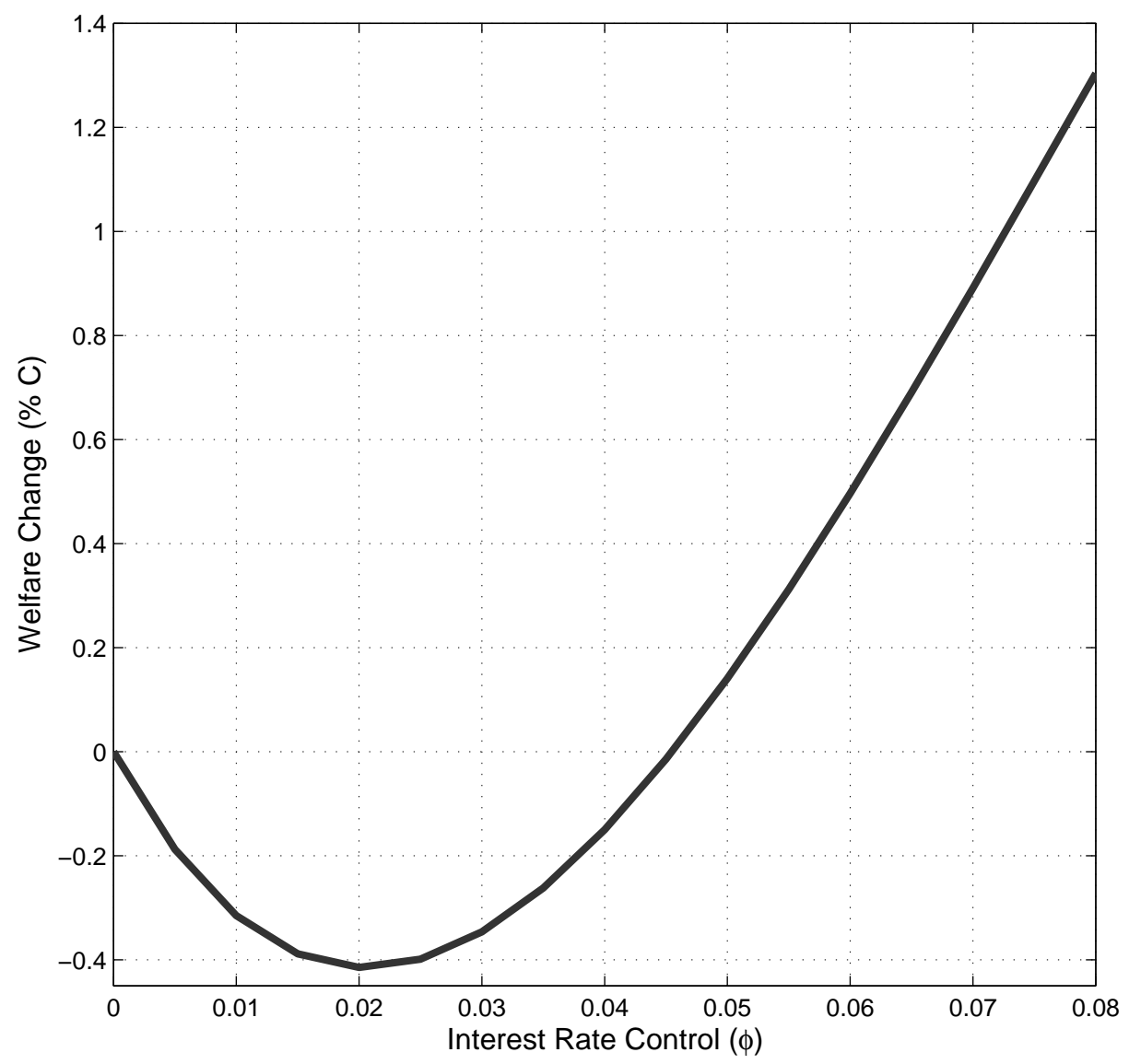

FiguRE 4. Welfare effects of interest-rate liberalization during the transition process. Welfare is measured by consumption equivalence. A point on the line represents the welfare gain (or loss) when the initial interest-rate wedge $(\phi)$ is removed. If the welfare change is negative, then removing the interest-rate wedge reduces welfare relative to the pre-liberalization regime. 

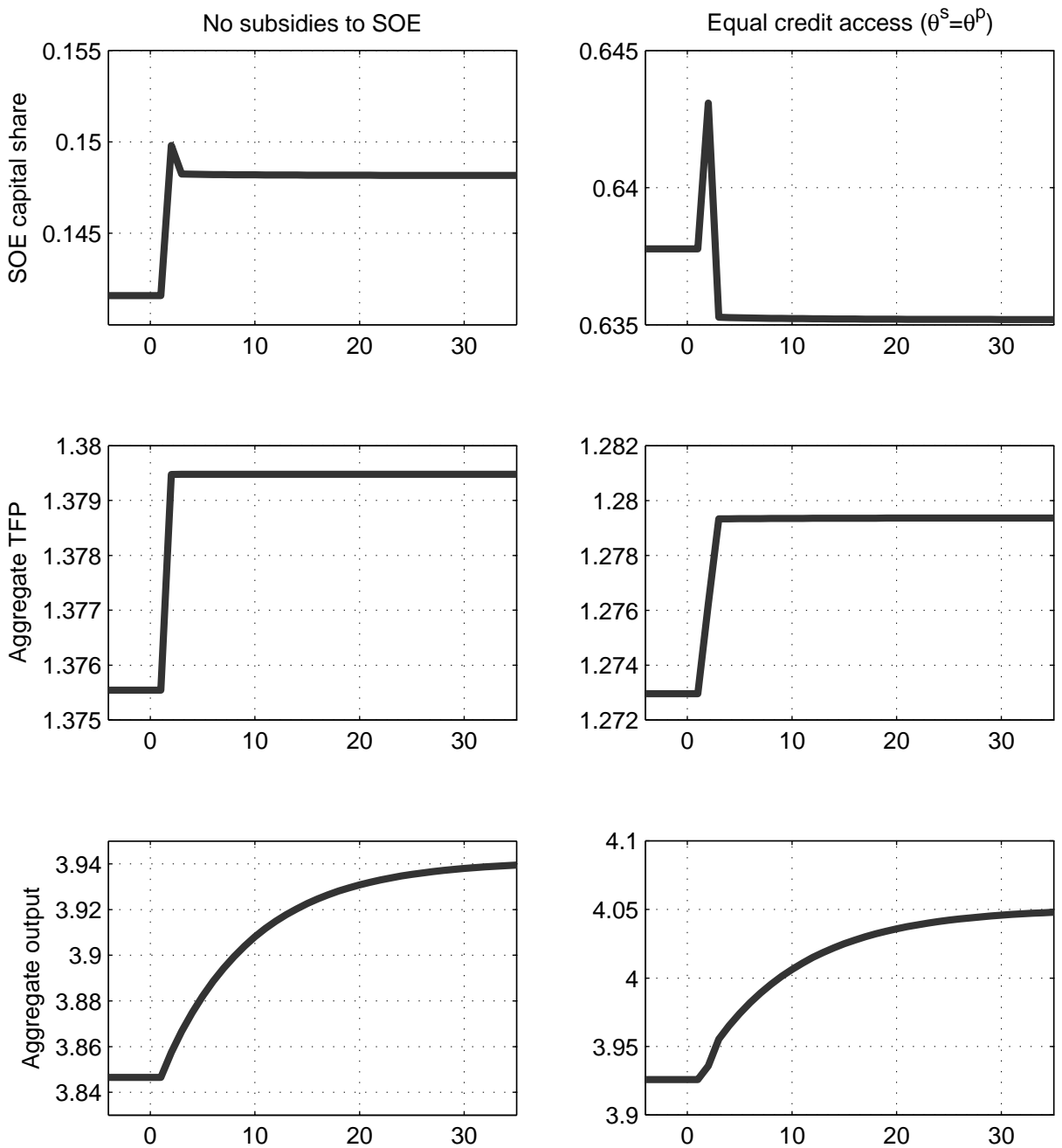

FiguRE 5. Transition dynamics following interest-rate liberalization in two counterfactual models: (i) no SOE subsidies $\left(\tau^{s}=1\right.$ ); (ii) equal credit access across the two sector $\left(\theta^{s}=\theta^{p}\right)$. 

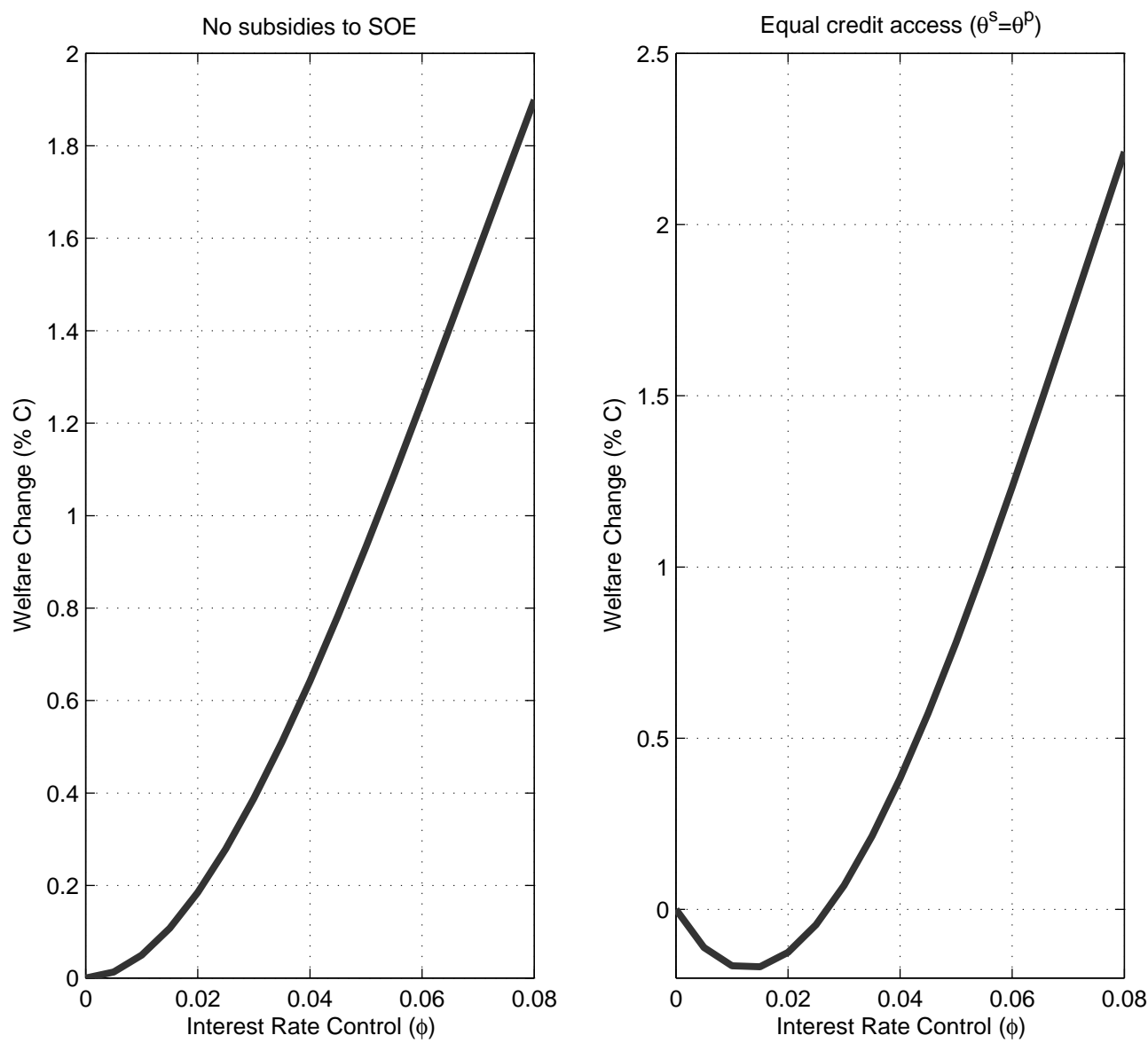

FiguRE 6. Welfare effects of interest-rate liberalization during the transition process in the counterfactual models with no SOE subsidies (the left panel) or equal credit access across the two sectors (the right panel). A point on the line represents the welfare gain (or loss) when the initial interest-rate wedge $(\phi)$ is removed. If the welfare change is negative, then removing the interest-rate wedge reduces welfare relative to the pre-liberalization regime. 


\section{Appendix}

\section{Appendix A. Proofs of propositions}

Proposition 1. Assume that the interest-rate wedge is sufficiently large so that $\phi>\tau z^{s}-z^{p}$. Then the only equilibrium is one with financial autarky, under which $k^{s}=k^{p}=h$ and $r_{d} \in\left[\tau z^{s}-\phi, z^{p}\right]$. Aggregate output is given by

$$
Y=(1-\mu) z^{p} h+\mu z^{s} h
$$

Proof. There are three possible cases for the deposit rate: (i) $r_{d}<\tau z^{s}-\phi$, (ii) $r_{d}>z^{p}$, and (iii) $r_{d} \in\left[\tau z^{s}-\phi, z^{p}\right]$. We show that the first two cases are not consistent with any equilibrium. We also show that, in the third case, there is an autarkic equilibrium, with no borrowing or lending between the two sectors.

If $r_{d}<\tau z^{s}-\phi$, then the SOEs' private MPK $\tau z^{s}$ exceeds the loan interest rate $r_{d}+\phi=r_{l}$. The borrowing constraint for SOEs will be binding, such that $l^{s}=\theta^{s} h$. However, under the assumption that $\phi>\tau z^{s}-z^{p}$, we have $r_{d}<\tau z^{s}-\phi<z^{p}$. That is, POEs' MPK exceeds the deposit rate, so that they choose not to save (i.e., $s^{p}=0$ ). But this contradicts the loan market clearing condition since $s^{p}=0$ implies $l^{s}=0$.

If $r_{d}>z^{p}$, then POEs would choose to save instead of producing since their MPK is lower than the deposit rate. This implies that $s^{p}=h$. However, in this case, $\tau z^{s}<z^{p}+\phi<$ $r_{d}+\phi=r_{l}$. Thus, SOEs would choose not to borrow (so that $l^{s}=0$ ) since the loan rate exceeds their private MPK. The positive saving by POEs and zero borrowing by SOEs again violates the loan market-clearing condition and cannot be an equilibrium.

In the case with $r_{d} \in\left[\tau z^{s}-\phi, z^{p}\right]$, however, there is an equilibrium. In particular, since $r_{d}<z^{p}<\tau z^{s}$, firms in both sectors choose not to save. They do not borrow either because the loan rate exceeds their MPKs (i.e., $r_{d}+\phi>\tau z^{s}>z^{p}$ ). Thus, the only equilibrium is the financial autarky with no between-sector capital flows. In this equilibrium, we have $k^{s}=k^{p}=h$ and aggregate output is given by $Y=(1-\mu) z^{p} h+\mu z^{s} h$.

Proposition 2. Assume that $\tau z^{s}>z^{p}>z^{s}$. In the liberalized economy with $\phi=0$, the equilibrium deposit rate satisfies $r_{d} \in\left[z^{p}, \tau z^{s}\right]$ and aggregate output $Y$ is given by

$$
Y=\left\{\begin{array}{cl}
z^{p} h-\left(z^{p}-z^{s}\right) \mu\left(1+\theta^{s}\right) h & \text { if } \theta^{s}<1 / \mu-1, \\
z^{s} h & \text { if } \theta^{s} \geq 1 / \mu-1 .
\end{array}\right.
$$

Proof. Since $\phi=0$, the loan rate and the deposit rate are identical (i.e., $r_{l}=r_{d}$ ). Following the same logic as in the proof of Proposition 1, we can show that $r_{d}<z^{p}$ and $r_{d}>\tau z^{s}$ are both inconsistent with an equilibrium. The equilibrium interest rate thus lies in the closed interval $\left[z^{p}, \tau z^{s}\right]$, which is non-empty under our assumption. 
If $r_{d}=z^{p}$, then POEs are indifferent between saving or not. Since $\tau z^{s}>z^{p}=r_{d}$, SOEs will choose not to save but to borrow up to the limit (i.e., $s^{s}=0$ and $l^{s}=\theta^{s} h$ ). The capital stock held by each SOE firm would be $k^{s}=\left(1+\theta^{s}\right) h$. The capital marketclearing condition (10) implies that $(1-\mu) k^{p}+\mu\left(1+\theta^{s}\right) h=h$. Thus, POEs would stay operating (i.e., $k^{p}>0$ ) if and only if $\theta^{s}<\frac{1}{\mu}-1$. In this case, aggregate output is given by $Y=(1-\mu) z^{p} k^{p}+\mu z^{s} k^{s}=z^{p} h-\left(z^{p}-z^{s}\right) \mu\left(1+\theta^{s}\right) h$.

If $r_{d} \in\left(z^{p}, \tau z^{s}\right]$, then POEs would choose to save all their endowment (i.e., $s^{p}=h$ ). The capital market-clearing condition (10) implies that SOEs will own all capital stock in the economy provided that $\theta^{s} \geq \frac{1}{\mu}-1$. In this case, aggregate output is given by $Y=z^{s} h$.

Proposition 3. In the economy with heterogeneous firms, there exist two threshold levels of idiosyncratic productivity, denoted by $\underline{\varepsilon}^{j}$ and $\bar{\varepsilon}^{j}$ for each sector $j \in\{s, p\}$, such that

$$
\begin{aligned}
& s^{j}(\varepsilon)=\left\{\begin{array}{ll}
h & \text { if } \varepsilon_{\min } \leq \varepsilon<\underline{\varepsilon}^{j} \\
0 & \text { if } \underline{\varepsilon}^{j} \leq \varepsilon
\end{array},\right. \\
& l^{j}(\varepsilon)=\left\{\begin{array}{cc}
0 & \text { if } \varepsilon_{\min } \leq \varepsilon<\bar{\varepsilon}^{j} \\
\theta^{j} h & \text { if } \bar{\varepsilon}^{j} \leq \varepsilon
\end{array}\right. \\
& k^{j}(\varepsilon)=\left\{\begin{array}{cc}
0 & \text { if } \varepsilon_{\min } \leq \varepsilon<\underline{\varepsilon}^{j} \\
h & \text { if } \underline{\varepsilon}^{j} \leq \varepsilon<\bar{\varepsilon}^{j} \\
\left(1+\theta^{j}\right) h & \text { if } \bar{\varepsilon}^{j} \leq \varepsilon
\end{array}\right.
\end{aligned}
$$

where the thresholds $\underline{\varepsilon}^{j}$ and $\bar{\varepsilon}^{j}$ are defined as

$$
\begin{aligned}
\underline{\varepsilon}^{j} & =\frac{r_{d}}{z^{j} \tau^{j}}, \\
\bar{\varepsilon}^{j} & =\frac{r_{d}+\phi}{z^{j} \tau^{j}} .
\end{aligned}
$$

Proof. The optimization problem of the firm in $j$ sector can be written as

$$
\max _{\left\{l^{j}(\varepsilon), s^{j}(\varepsilon)\right\}} \tau^{j} z^{j} \varepsilon\left[h+l^{j}(\varepsilon)-s^{j}(\varepsilon)\right]-r_{l} l^{j}(\varepsilon)+r_{d} s^{j}(\varepsilon),
$$

subject to

$$
\begin{aligned}
& 0 \leq l^{j}(\varepsilon) \leq \theta^{j} h, \\
& 0 \leq s^{j}(\varepsilon) \leq h .
\end{aligned}
$$

Because of the linearity, we can define two cutoffs as $\underline{\varepsilon}^{j}=\frac{r_{d}}{z^{j} \tau^{j}}$ and $\bar{\varepsilon}^{j}=\frac{r_{l}}{z^{j} \tau^{j}}$, where $r_{l}=r_{d}+\phi$. For $\varepsilon<\underline{\varepsilon}^{j}$, production is not profitable because because $\tau^{j} z^{j} \varepsilon<r_{d}$. Thus, in this case, the firm chooses to save, i.e., $s^{j}(\varepsilon)=h, l^{j}(\varepsilon)=0$ and $k^{j}(\varepsilon)=0$. If $\varepsilon \in\left[\underline{\varepsilon}^{j}, \bar{\varepsilon}^{j}\right)$, then production yields higher returns than saving, but the return is still lower than the borrowing costs (i.e., $r_{d} \leq \tau^{j} z^{j} \varepsilon<r_{l}$ ). In this case, the firm's optimal decision is to produce 
and self-finance its production. That is, $s^{j}(\varepsilon)=l^{j}(\varepsilon)=0$ and $k^{j}(\varepsilon)=h$. If $\varepsilon \geq \bar{\varepsilon}^{j}$, then we have $\tau^{j} z^{j} \varepsilon \geq r_{l}$ and the firm chooses to borrow to finance production. Therefore, in this case the borrowing constraint is binding, and we have $s^{j}(\varepsilon)=0, l^{j}(\varepsilon)=\theta^{j} h$ and $k^{j}(\varepsilon)=\left(1+\theta^{j}\right) h$.

Proposition 4 . The deposit rate $r_{d}$ decreases with the interest-rate wedge $\phi$ and the lending rate $r_{l}$ increases with $\phi$. Thus, interest-rate liberalization (that lowers $\phi$ ) would raise the deposit rate $r_{d}$ and reduce the lending rate $r_{l}$.

Proof. Denote the probability density function of $\varepsilon$ as $f^{j}(\varepsilon), j \in\{s, p\}$. The capital marketclearing condition (22) implies that

$$
1=\mu\left[\int_{\underline{\varepsilon}^{s}}^{\varepsilon_{\max }} d \mathbf{F}^{s}(\varepsilon)+\theta^{s} \int_{\bar{\varepsilon}^{s}}^{\varepsilon_{\max }} d \mathbf{F}^{s}(\varepsilon)\right]+(1-\mu)\left[\int_{\underline{\varepsilon}^{p}}^{\varepsilon_{\max }} d \mathbf{F}^{p}(\varepsilon)+\theta^{p} \int_{\bar{\varepsilon}^{p}}^{\varepsilon_{\max }} d \mathbf{F}^{p}(\varepsilon)\right],
$$

where

$$
\begin{aligned}
\underline{\varepsilon}^{s} & =\frac{r_{d}}{z^{s} \tau}, \bar{\varepsilon}^{s}=\frac{r_{d}+\phi}{z^{s} \tau}, \\
\underline{\varepsilon}^{p} & =\frac{r_{d}}{z^{p}}, \bar{\varepsilon}^{p}=\frac{r_{d}+\phi}{z^{p}} .
\end{aligned}
$$

Differentiating both sides with respect to $\phi$ yields

$0=\frac{\mu}{z^{s} \tau}\left\{\left[f^{s}\left(\underline{\varepsilon}^{s}\right)+\theta^{s} f^{s}\left(\bar{\varepsilon}^{s}\right)\right] \frac{\partial r_{d}}{\partial \phi}+\theta^{s} f^{s}\left(\bar{\varepsilon}^{s}\right)\right\}+\frac{1-\mu}{z^{p}}\left\{\left[f^{p}\left(\underline{\varepsilon}^{p}\right)+\theta^{p} f^{p}\left(\bar{\varepsilon}^{p}\right)\right] \frac{\partial r_{d}}{\partial \phi}+\theta^{p} f^{p}\left(\bar{\varepsilon}^{p}\right)\right\}$.

With some algebra, we obtain

$$
\frac{\partial r_{d}}{\partial \phi}=-\frac{1}{1+\psi}
$$

where

$$
\psi=\frac{\mu f^{s}\left(\underline{\varepsilon}^{s}\right)+(1-\mu) f^{p}\left(\underline{\varepsilon}^{p}\right) \frac{\tau z^{s}}{z^{p}}}{\mu f^{s}\left(\bar{\varepsilon}^{s}\right) \theta^{s}+(1-\mu) f^{p}\left(\bar{\varepsilon}^{p}\right) \frac{\tau z^{s}}{z^{p}} \theta^{p}} .
$$

Since $\psi>0$, we have $\frac{\partial r_{d}}{\partial \phi}<0$ and $\frac{\partial\left(r_{d}+\phi\right)}{\partial \phi}>0$. That is, the interest-rate liberalization reduces the deposit rate $r_{d}$ but raises the lending rate $r_{d}+\phi$.

Proposition 5. Assume that the idiosyncratic shocks in the two sectors are drawn from the same distribution, with the probability density function $f(\varepsilon)$. Assume further that the density function satisfies the condition that $g(\varepsilon) \equiv \frac{f^{\prime}(\varepsilon) \varepsilon}{f(\varepsilon)}$ decreases with $\varepsilon$. Under these conditions, we obtain

$$
\frac{\partial K^{s}}{\partial \phi}<0, \quad \frac{\partial K^{p}}{\partial \phi}>0 .
$$

We also obtain $\frac{\partial A^{p}}{\partial \phi}<0$, whereas $\frac{\partial A^{s}}{\partial \phi}$ has an ambiguous sign. Furthermore, the relation between aggregate output and the interest-rate wedge is also ambiguous (i.e., $\frac{\partial Y}{\partial \phi}$ has an ambiguous sign). The same is true for aggregate TFP. 
Proof. We first discuss how liberalization affects the capital flows across sectors. For any $\phi>0$, the capitals in two sectors are given by

$$
\begin{aligned}
& K^{s}=\mu h\left[\int_{\underline{\varepsilon}^{s}}^{\infty} f(\varepsilon) d \varepsilon+\theta^{s} \int_{\bar{\varepsilon}^{s}}^{\infty} f(\varepsilon) d \varepsilon\right], \\
& K^{p}=(1-\mu) h\left[\int_{\underline{\varepsilon}^{p}}^{\infty} f(\varepsilon) d \varepsilon+\theta^{p} \int_{\bar{\varepsilon}^{p}}^{\infty} f(\varepsilon) d \varepsilon\right] .
\end{aligned}
$$

where cutoffs are defined in (A.12) and (A.13). The partial derivative $\frac{\partial K^{s}}{\partial \phi}$ is

$$
\frac{\partial K^{s}}{\partial \phi}=-\mu h\left[f\left(\underline{\varepsilon}^{s}\right) \frac{\partial \underline{\varepsilon}^{s}}{\partial \phi}+\theta^{s} f\left(\bar{\varepsilon}^{s}\right) \frac{\partial \bar{\varepsilon}^{s}}{\partial \phi}\right] .
$$

According to the definition of cutoffs, we have $\frac{\partial \underline{\varepsilon}^{s}}{\partial \phi}=\frac{1}{z^{s} \tau} \frac{\partial r_{d}}{\partial \phi}$ and $\frac{\partial \bar{\varepsilon}^{s}}{\partial \phi}=\frac{1}{z^{s} \tau}\left(1+\frac{\partial r_{d}}{\partial \phi}\right)$, where $\frac{\partial r_{d}}{\partial \phi}=-\frac{1}{1+\psi}$ (see A.15). Then we have

$$
\begin{aligned}
\frac{\partial K^{s}}{\partial \phi} & =-\frac{\mu h}{z^{s} \tau}\left\{\left[f\left(\underline{\varepsilon}^{s}\right)+\theta^{s} f\left(\bar{\varepsilon}^{s}\right)\right] \frac{\partial r_{d}}{\partial \phi}+\theta^{s} f\left(\bar{\varepsilon}^{s}\right)\right\} \\
& =\frac{\mu h}{z^{s} \tau} \frac{f\left(\underline{\varepsilon}^{s}\right)+\theta^{s} f\left(\bar{\varepsilon}^{s}\right)-\theta^{s} f\left(\bar{\varepsilon}^{s}\right)(1+\psi)}{1+\psi} .
\end{aligned}
$$

We now rewrite $\frac{\partial K^{s}}{\partial \phi}$ more compactly. Replacing $\psi$ in the numerator of the last equation with (A.16) yields

$$
\begin{aligned}
\frac{\partial K^{s}}{\partial \phi} & =\frac{\mu h}{z^{s} \tau(1+\psi)}\left\{f\left(\underline{\varepsilon}^{s}\right)+\theta^{s} f\left(\bar{\varepsilon}^{s}\right)-\theta^{s} f\left(\bar{\varepsilon}^{s}\right)\left[1+\frac{\mu f\left(\underline{\varepsilon}^{s}\right)+(1-\mu) f\left(\underline{\varepsilon}^{p}\right) \frac{\tau z^{s}}{z^{p}}}{\mu f\left(\bar{\varepsilon}^{s}\right) \theta^{s}+(1-\mu) f\left(\bar{\varepsilon}^{p}\right) \frac{\tau z^{s}}{z^{p}} \theta^{p}}\right]\right\} \\
& =\frac{\mu h(1-\mu)}{z^{p}(1+\psi)} \frac{f\left(\underline{\varepsilon}^{s}\right) f\left(\bar{\varepsilon}^{p}\right) \theta^{p}-\theta^{s} f\left(\bar{\varepsilon}^{s}\right) f\left(\underline{\varepsilon}^{p}\right)}{\mu f\left(\bar{\varepsilon}^{s}\right) \theta^{s}+(1-\mu) f\left(\bar{\varepsilon}^{p}\right) \frac{\tau z^{s}}{z^{p}} \theta^{p}} \\
& =\frac{h(1-\mu) f\left(\underline{\varepsilon}^{s}\right)}{z^{p}(1+\psi)} \frac{\frac{f\left(\bar{\varepsilon}^{p}\right)}{f\left(\bar{\varepsilon}^{s}\right)} \frac{\theta^{p}}{\theta^{s}}-\frac{f\left(\underline{\varepsilon}^{p}\right)}{f\left(\underline{\varepsilon}^{s}\right)}}{1+\frac{1-\mu}{\mu} \frac{f\left(\bar{\varepsilon}^{p}\right)}{f\left(\bar{\varepsilon}^{s}\right)} \frac{\tau z^{s}}{z^{p}} \frac{\theta^{p}}{\theta^{s}}} \\
& =\chi_{1}\left[\frac{f\left(\bar{\varepsilon}^{p}\right)}{f\left(\bar{\varepsilon}^{s}\right)} \frac{\theta^{p}}{\theta^{s}}-\frac{f\left(\underline{\varepsilon}^{p}\right)}{f\left(\underline{\varepsilon}^{s}\right)}\right],
\end{aligned}
$$

where $\chi_{1}=\frac{h(1-\mu) f\left(\varepsilon^{s}\right)}{z^{p}(1+\psi)\left[1+\frac{1-\mu}{\mu} \frac{f\left(\bar{\varepsilon}^{p}\right)}{f\left(\bar{\varepsilon}^{s}\right)} \frac{\tau z^{s}}{z^{p}} \frac{\theta^{p}}{\theta^{s}}\right]}$. The third line is obtained by dividing the numerator and the denominator simultaneously by $\mu \theta^{s} f\left(\bar{\varepsilon}^{s}\right) f\left(\underline{\varepsilon}^{s}\right)$.

The assumption that $\frac{f^{\prime}(\varepsilon) \varepsilon}{f(\varepsilon)}$ is decreasing in $\varepsilon$ implies $\frac{f(\varkappa \varepsilon)}{f(\varepsilon)}$, for any $\varkappa>1$, is decreasing in $\varepsilon$. As a result, the condition $\tau z^{s}>z^{p}$ ensures $\frac{f\left(\frac{r_{d}+\phi}{r_{d}} \underline{\varepsilon}^{s}\right)}{f\left(\underline{\varepsilon}^{s}\right)} \geq \frac{f\left(\frac{r_{d}+\phi}{r_{d}} \underline{\varepsilon}^{p}\right)}{f\left(\underline{\varepsilon}^{p}\right)}$, or equivalently $\frac{f\left(\bar{\varepsilon}^{s}\right)}{f\left(\underline{\varepsilon}^{s}\right)} \frac{f\left(\varepsilon^{p}\right)}{f\left(\bar{\varepsilon}^{p}\right)} \geq$ 1. Notice that the monotonicity assumption of $\frac{f^{\prime}(\varepsilon) \varepsilon}{f(\varepsilon)}$ is fairly weak and can be satisfied by many commonly used distributions, for instance, log-normal or Pareto distributions. Moreover, $\theta^{p}<\theta^{s}$ further implies $\frac{f\left(\bar{\varepsilon}^{s}\right) f\left(\varepsilon^{p}\right)}{f\left(\bar{\varepsilon}^{p}\right) f\left(\underline{\varepsilon}^{s}\right)} \geq 1>\frac{\theta^{p}}{\theta^{s}}$ such that the second term in (A.22) is negative, i.e., $\frac{f\left(\bar{\varepsilon}^{p}\right) \theta^{p}}{f\left(\bar{\varepsilon}^{s}\right) \theta^{s}}-\frac{f\left(\underline{\varepsilon}^{p}\right)}{f\left(\underline{\varepsilon}^{s}\right)}<0$. Therefore, $\frac{\partial K^{s}}{\partial \phi}<0$. The capital market-clearing condition $K^{s}+K^{p}=h$ immediately gives $\frac{\partial K^{p}}{\partial \phi}>0$. 
We now discuss the effects on output. According to the definition of sectoral output, we have

$$
Y^{j}=\mu^{j} z^{j} h\left[\int_{\underline{\varepsilon}^{j}}^{\infty} \varepsilon f(\varepsilon) d \varepsilon+\theta^{j} \int_{\bar{\varepsilon}^{j}}^{\infty} \varepsilon f(\varepsilon) d \varepsilon\right], j \in\{s, p\},
$$

where $\mu^{s}=\mu, \mu^{p}=1-\mu$.

We first look at the SOE sector. The impact of interest-rate liberalization on the output is

$$
\begin{aligned}
\frac{\partial Y^{s}}{\partial \phi} & =\mu h z^{s}\left[-\underline{\varepsilon}^{s} f\left(\underline{\varepsilon}^{s}\right) \frac{\partial \underline{\varepsilon}^{s}}{\partial \phi}-\theta^{s} \bar{\varepsilon}^{s} f\left(\bar{\varepsilon}^{s}\right) \frac{\partial \bar{\varepsilon}^{s}}{\partial \phi}\right] \\
& =\frac{\mu h}{\tau}\left\{-\left[\underline{\varepsilon}^{s} f\left(\underline{\varepsilon}^{s}\right)+\theta^{s} \bar{\varepsilon}^{s} f\left(\bar{\varepsilon}^{s}\right)\right] \frac{\partial r_{d}}{\partial \phi}-\theta^{s} \bar{\varepsilon}^{s} f\left(\bar{\varepsilon}^{s}\right)\right\} \\
& =\frac{\mu h}{\tau}\left\{\left[\underline{\varepsilon}^{s} f\left(\underline{\varepsilon}^{s}\right)+\theta^{s} \bar{\varepsilon}^{s} f\left(\bar{\varepsilon}^{s}\right)\right] \frac{1}{1+\psi}-\theta^{s} \bar{\varepsilon}^{s} f\left(\bar{\varepsilon}^{s}\right)\right\} \\
& =\frac{\mu h}{\tau} \frac{\underline{\varepsilon}^{s} f\left(\underline{\varepsilon}^{s}\right)+\theta^{s} \bar{\varepsilon}^{s} f\left(\bar{\varepsilon}^{s}\right)-\theta^{s} \bar{\varepsilon}^{s} f\left(\bar{\varepsilon}^{s}\right)(1+\psi)}{1+\psi} .
\end{aligned}
$$

The second and third lines are due to the definition of cutoffs and (A.15). Replacing $\psi$ in the numerator of the last equation by (A.16) and rearranging terms yield

$$
\begin{aligned}
\frac{\partial Y^{s}}{\partial \phi} & =\frac{1}{\tau}\left\{r_{d} \chi_{1}\left[\frac{f\left(\bar{\varepsilon}^{p}\right) \theta^{p}}{f\left(\bar{\varepsilon}^{s}\right) \theta^{s}}-\frac{f\left(\underline{\varepsilon}^{p}\right)}{f\left(\underline{\varepsilon}^{s}\right)}\right]+\chi_{1} \frac{\mu\left(\underline{\varepsilon}^{s}-\bar{\varepsilon}^{s}\right) z^{p}}{1-\mu}\left[1+\frac{f\left(\underline{\varepsilon}^{p}\right)}{f\left(\underline{\varepsilon}^{s}\right)} \frac{1-\mu}{\mu} \frac{\tau z^{s}}{z^{p}}\right]\right\} \\
& =\frac{1}{\tau}\left(r_{d} \frac{\partial K^{s}}{\partial \phi}-\frac{\mu}{1-\mu} \frac{z^{p}}{z^{s} \tau} \chi_{1} \chi_{2} \phi\right)
\end{aligned}
$$

where $\chi_{1}=\frac{h(1-\mu) f\left(\varepsilon^{s}\right)}{z^{p}(1+\psi)\left[1+\frac{1-\mu}{\mu} \frac{f\left(\bar{\varepsilon}^{p}\right)}{f\left(\bar{\varepsilon}^{s}\right)} \frac{\tau z^{s}}{z^{p}} \frac{\theta^{p}}{\theta^{s}}\right]}$ and $\chi_{2}=1+\frac{1-\mu}{\mu} \frac{z^{s} \tau}{z^{p}} \frac{f\left(\underline{\varepsilon}^{p}\right)}{f\left(\underline{\varepsilon}^{s}\right)}$. The second line is obtained by replacing $\chi_{1}\left[\frac{f\left(\bar{\varepsilon}^{p}\right) \theta^{p}}{f\left(\bar{\varepsilon}^{s}\right) \theta^{s}}-\frac{f\left(\underline{\varepsilon}^{p}\right)}{f\left(\underline{\varepsilon}^{s}\right)}\right]$ with $\frac{\partial K^{s}}{\partial \phi}$.

Since $\frac{\partial K^{s}}{\partial \phi}<0, \chi_{1}, \chi_{2}>0$, we have $\frac{\partial Y^{s}}{\partial \phi}<0$, i.e., the interest rate liberalization (reducing $\phi)$ will unambiguously increase SOE output.

For the POE sector, similarly we have

$$
\begin{aligned}
\frac{\partial Y^{p}}{\partial \phi} & =(1-\mu) z^{p} h\left[-\underline{\varepsilon}^{p} f\left(\underline{\varepsilon}^{p}\right) \frac{\partial \underline{\varepsilon}^{p}}{\partial \phi}-\theta^{p} \bar{\varepsilon}^{p} f\left(\bar{\varepsilon}^{p}\right) \frac{\partial \bar{\varepsilon}^{p}}{\partial \phi}\right] \\
& =(1-\mu) h \frac{\underline{\varepsilon}^{p} f\left(\underline{\varepsilon}^{p}\right)+\theta^{p} \bar{\varepsilon}^{p} f\left(\bar{\varepsilon}^{p}\right)-\theta^{p} \bar{\varepsilon}^{p} f\left(\bar{\varepsilon}^{p}\right)(1+\psi)}{1+\psi} .
\end{aligned}
$$

Replacing $\psi$ in the numerator of the last equation by (A.16) and rearranging terms yield

$$
\begin{aligned}
\frac{\partial Y^{p}}{\partial \phi} & =\chi_{1}\left[r_{d} \frac{f\left(\underline{\varepsilon}^{p}\right)}{f\left(\underline{\varepsilon}^{s}\right)}-\left(r_{d}+\phi\right) \frac{\theta^{p}}{\theta^{s}} \frac{f\left(\bar{\varepsilon}^{p}\right)}{f\left(\bar{\varepsilon}^{s}\right)}-\frac{1-\mu}{\mu} \frac{f\left(\underline{\varepsilon}^{p}\right) f\left(\bar{\varepsilon}^{p}\right)}{f\left(\underline{\varepsilon}^{s}\right) f\left(\bar{\varepsilon}^{s}\right)} \frac{\tau z^{s}}{z^{p}} \frac{\theta^{p}}{\theta^{s}} \phi\right] \\
& =r_{d} \frac{\partial K^{p}}{\partial \phi}-\frac{\theta^{p}}{\theta^{s}} \frac{f\left(\bar{\varepsilon}^{p}\right)}{f\left(\bar{\varepsilon}^{s}\right)} \chi_{1} \chi_{2} \phi .
\end{aligned}
$$

The second line is obtained by replacing $\chi_{1}\left[\frac{f\left(\underline{\varepsilon}^{p}\right)}{f\left(\underline{\varepsilon}^{s}\right)}-\frac{f\left(\bar{\varepsilon}^{p}\right) \theta^{p}}{f\left(\bar{\varepsilon}^{s}\right) \theta^{s}}\right]$ with $\frac{\partial K^{p}}{\partial \phi}$. 
Since the liberalization causes capital outflow $\left(\frac{\partial K^{p}}{\partial \phi}>0\right)$ and efficiency improvement (see the proof below), the total effect on $Y^{p}$ is ambiguous. We now discuss the effects on sectoral TFPs. The TFPs are defined as $A^{j}=\frac{Y^{j}}{K^{j}}$, therefore

$$
\frac{\partial A^{j}}{\partial \phi}=\frac{1}{K^{j}}\left[\frac{\partial Y^{j}}{\partial \phi}-A^{j} \frac{\partial K^{j}}{\partial \phi}\right]
$$

Equations (A.18), (A.19), (A.25) and (A.27), imply

$$
\begin{aligned}
\frac{\partial A^{s}}{\partial \phi} & =\frac{1}{K^{s}}\left[\left(z^{s} \underline{\varepsilon}^{s}-A^{s}\right) \frac{\partial K^{s}}{\partial \phi}-\frac{\mu}{1-\mu} \frac{z^{p}}{z^{s} \tau^{2}} \chi_{1} \chi_{2} \phi\right], \\
\frac{\partial A^{p}}{\partial \phi} & =\frac{1}{K^{p}}\left[\left(z^{p} \underline{\varepsilon}^{p}-A^{p}\right) \frac{\partial K^{p}}{\partial \phi}-\frac{f\left(\bar{\varepsilon}^{p}\right) \theta^{p}}{f\left(\bar{\varepsilon}^{s}\right) \theta^{s}} \chi_{1} \chi_{2} \phi\right] .
\end{aligned}
$$

The impact of interest-rate liberalization on TFP consists of two components. The first term in the blanket $\left(z^{j} \underline{\varepsilon}^{j}-A^{j}\right) \frac{\partial K^{j}}{\partial \phi}$ reflects the effect of the between-sector capital flows on efficiency. Given that $z^{j} \underline{\varepsilon}^{j}<A^{j}$, interest-rate liberalization has a negative effect on SOE's TFP because it leads to capital inflows to that sector $\left(\frac{\partial K^{s}}{\partial \phi}<0\right)$, but a positive effect on POE's TFP because it results in capital outflows from that sector $\left(\frac{\partial K^{p}}{\partial \phi}>0\right)$.

The second term in the blanket reflects the direct impact of interest rate liberalization on the each sector's productivity. This term is negative, implying that interest-rate liberalization (reducing $\phi$ ) improves productivity for both sectors.

Combining these two effects, we infer that interest-rate liberalization improves TFP in the POE sector but has ambiguous effect on SOE productivity.

The effect of liberalization on aggregate output is given by

$$
\frac{\partial Y}{\partial \phi}=\frac{\partial Y^{s}}{\partial \phi}+\frac{\partial Y^{p}}{\partial \phi}=\frac{r_{d}}{z^{p}}\left(\frac{1}{\tau}-1\right) \frac{\partial K^{s}}{\partial \phi}-\chi_{1} \chi_{2} \phi\left[\frac{\mu}{1-\mu} \frac{1}{z^{s} \tau^{2}}+\frac{f\left(\bar{\varepsilon}^{p}\right) \theta^{p}}{f^{s}\left(\bar{\varepsilon}^{s}\right) \theta^{s}} \frac{1}{z^{p}}\right] .
$$

Under the condition $\tau>1$ (due to $z^{s}<z^{p}$ and $\tau z^{s}>z^{p}$ ), interest-rate liberalization has two opposing effects on aggregate output (the first term is positive and the second term is negative). Thus, the net effect on aggregate output can be ambiguous.

Proposition 6. Assume that the idiosyncratic shock is drawn from the interval $\left(\varepsilon_{\min }^{j}, \varepsilon_{\max }^{j}\right)$ according to the distribution function $F^{j}(\varepsilon)$. Then, given $h_{t}^{j}$, the optimal allocations of saving $s_{t}^{j}$, borrowing $l_{t}^{j}$, and capital input $k_{t}^{j}$ are determined by

$$
\begin{aligned}
& s_{t}^{j}=\left\{\begin{array}{cc}
{\left[1-\left(\varepsilon_{t}^{j} / \underline{\varepsilon}_{t}^{j}\right)^{\frac{\tilde{\alpha}}{1-\tilde{\alpha}}}\right] h_{t}^{j}} & \text { if } \varepsilon_{\min }^{j} \leq \varepsilon_{t}^{j}<\underline{\varepsilon}_{t}^{j} \\
0 & \text { if } \underline{\varepsilon}_{t}^{j} \leq \varepsilon_{t}^{j}<\varepsilon_{\max }^{j}
\end{array},\right. \\
& l_{t}^{j}=\left\{\begin{array}{cc}
0 & \text { if } \varepsilon_{\min }^{j} \leq \varepsilon_{t}^{j}<\hat{\varepsilon}_{t}^{j} \\
{\left[\left(\varepsilon_{t}^{j} / \hat{\varepsilon}_{t}^{j}\right)^{\frac{\tilde{\alpha}}{1-\tilde{\alpha}}}-1\right] h_{t}^{j}} & \text { if } \hat{\varepsilon}_{t}^{j} \leq \varepsilon_{t}^{j}<\bar{\varepsilon}_{t}^{j} \\
\theta^{j} h_{t}^{j} & \text { if } \bar{\varepsilon}_{t}^{j} \leq \varepsilon_{t}^{j}<\varepsilon_{\max }^{j}
\end{array},\right.
\end{aligned}
$$




$$
k_{t}^{j}=\left\{\begin{array}{cl}
\left(\varepsilon_{t}^{j} / \underline{\varepsilon}_{t}^{j}\right)^{\frac{\tilde{\alpha}}{1-\tilde{\alpha}}} h_{t}^{j} & \text { if } \varepsilon_{\min }^{j} \leq \varepsilon_{t}^{j}<\underline{\varepsilon}_{t}^{j} \\
h_{t}^{j} & \text { if } \underline{\varepsilon}_{t}^{j} \leq \varepsilon_{t}^{j}<\hat{\varepsilon}_{t}^{j} \\
\left(\varepsilon_{t}^{j} / \hat{\varepsilon}_{t}^{j}\right)^{\frac{\tilde{\alpha}}{1-\tilde{\alpha}}} h_{t}^{j} & \text { if } \hat{\varepsilon}_{t}^{j} \leq \varepsilon_{t}^{j}<\bar{\varepsilon}_{t}^{j} \\
\left(1+\theta^{j}\right) h_{t}^{j} & \text { if } \bar{\varepsilon}_{t}^{j} \leq \varepsilon_{t}^{j}<\varepsilon_{\max }^{j}
\end{array},\right.
$$

where the three cutoff points $\left\{\underline{\varepsilon}_{t}^{j}, \hat{\varepsilon}_{t}^{j}, \bar{\varepsilon}_{t}^{j}\right\}$ are defined as

$$
\begin{aligned}
\underline{\varepsilon}_{t}^{j} & =\left(h_{t}^{j}\right)^{\frac{1-\tilde{\alpha}}{\tilde{\alpha}}}\left[\frac{r_{d t}+\delta}{\tilde{\alpha} \tau^{j}\left(z^{j}\right)^{\tilde{\alpha}} R_{t}}\right]^{\frac{1}{\tilde{\alpha}}}, \\
\hat{\varepsilon}_{t}^{j} & =\left(h_{t}^{j}\right)^{\frac{1-\tilde{\alpha}}{\tilde{\alpha}}}\left[\frac{r_{l t}+\delta}{\tilde{\alpha} \tau^{j}\left(z^{j}\right)^{\tilde{\alpha}} R_{t}}\right]^{\frac{1}{\tilde{\alpha}}}, \\
\bar{\varepsilon}_{t}^{j} & =\left[\left(1+\theta^{j}\right) h_{t}^{j}\right]^{\frac{1-\tilde{\alpha}}{\tilde{\alpha}}}\left[\frac{r_{l t}+\delta}{\tilde{\alpha} \tau^{j}\left(z^{j}\right)^{\tilde{\alpha}} R_{t}}\right]^{\frac{1}{\tilde{\alpha}}} .
\end{aligned}
$$

The net worth $h_{t}^{j}$ can be solved from the envelope condition

$$
1=\beta \mathbf{E}_{t} \frac{\Lambda_{t+1}}{\Lambda_{t}} \int \frac{\partial V_{t+1}^{j}\left(h_{t+1}^{j}, \varepsilon_{t+1}^{j}\right)}{\partial h_{t+1}^{j}} d \mathbf{F}^{j}\left(\varepsilon_{t+1}^{j}\right) .
$$

Furthermore, $h_{t}^{j}$ is independent of the realized idiosyncratic shocks $\varepsilon_{t}^{j}$.

Proof. First, replacing $k_{t}^{j}$ by $l_{t}^{j}-s_{t}^{j}+h_{t}^{j}$ in the dividend equation yields

$$
d_{t}^{j}=\tau^{j} R_{t}\left[z^{j} \varepsilon_{t}^{j}\left(l_{t}^{j}+h_{t}^{j}-s_{t}^{j}\right)\right]^{\tilde{\alpha}}+(1-\delta) h_{t}^{j}+\left(\delta+r_{d t}\right) s_{t}^{j}-\left(\delta+r_{l t}\right) l_{t}^{j}-h_{t+1}^{j} .
$$

Given $h_{t}^{j}$ and $\varepsilon_{t}^{j}$, the first-order condition for $l_{t}^{j}$ that guarantees an interior solution for borrowing is given by

$$
\tilde{\alpha} \tau^{j} R_{t}\left(z^{j} \varepsilon_{t}^{j}\right)^{\tilde{\alpha}}\left(l_{t}^{j}+h_{t}^{j}-s_{t}^{j}\right)^{\tilde{\alpha}-1}=r_{l t}+\delta
$$

The first-order condition for $s_{t}^{j}$ that guarantees an interior solution for saving is given by

$$
\tilde{\alpha} \tau^{j} R_{t}\left(z^{j} \varepsilon_{t}^{j}\right)^{\tilde{\alpha}}\left(l_{t}^{j}+h_{t}^{j}-s_{t}^{j}\right)^{\tilde{\alpha}-1}=r_{d t}+\delta .
$$

Notice that the last two optimal conditions may not be satisfied simultaneously. We need to consider four different cases.

Case 1. $\varepsilon_{t}^{j} \geq \bar{\varepsilon}_{t}^{j} \equiv\left[\left(1+\theta^{j}\right) h_{t}^{j}\right]^{\frac{1-\tilde{\alpha}}{\tilde{\alpha}}}\left[\frac{r_{l t}+\delta}{\tilde{\alpha} \tau^{j}\left(z^{j}\right)^{\tilde{\alpha}} R_{t}}\right]^{\frac{1}{\tilde{\alpha}}}$. In this case, the firm's productivity is sufficiently high, so the borrowing constraint is binding. We then have

$$
\begin{aligned}
l_{t}^{j} & =\theta^{j} h_{t}^{j}, \\
k_{t}^{j} & =\left(1+\theta^{j}\right) h_{t}^{j}, \\
s_{t}^{j} & =0 \\
d_{t}^{j} & =\tau^{j} R_{t}\left[z^{j} \varepsilon_{t}^{j}\left(1+\theta^{j}\right) h_{t}^{j}\right]^{\tilde{\alpha}}+\left[(1-\delta)-\left(\delta+r_{l t}\right) \theta^{j}\right] h_{t}^{j}-h_{t+1}^{j} .
\end{aligned}
$$


Case 2. $\hat{\varepsilon}_{t}^{j} \leq \varepsilon_{t}^{j}<\bar{\varepsilon}_{t}^{j}$, where $\hat{\varepsilon}_{t}^{j} \equiv\left(h_{t}^{j}\right)^{\frac{1-\tilde{\alpha}}{\tilde{\alpha}}}\left[\frac{r_{l t}+\delta}{\tilde{\alpha} \tau^{j}\left(z^{j}\right)^{\tilde{\alpha}} R_{t}}\right]^{\frac{1}{\tilde{\alpha}}}$. In this case, the optimal loan $l_{t}^{j}$ is an interior solution. We then have

$$
\begin{aligned}
l_{t}^{j} & =\left[\left(\frac{\varepsilon_{t}^{j}}{\hat{\varepsilon}_{t}^{j}}\right)^{\frac{\tilde{\alpha}}{1-\tilde{\alpha}}}-1\right] h_{t}^{j}, \\
k_{t}^{j} & =\left(\frac{\varepsilon_{t}^{j}}{\hat{\varepsilon}_{t}^{j}}\right)^{\frac{\tilde{\alpha}}{1-\tilde{\alpha}}} h_{t}^{j}, \\
s_{t}^{j} & =0, \\
d_{t}^{j} & =\tau^{j} R_{t}\left[z^{j} \varepsilon_{t}^{j}\left(\frac{\varepsilon_{t}^{j}}{\hat{\varepsilon}_{t}^{j}}\right)^{\frac{\tilde{\alpha}}{1-\tilde{\alpha}}} h_{t}^{j}\right]^{\tilde{\alpha}} \\
& +\left\{(1-\delta)-\left(\delta+r_{l t}\right)\left[\left(\frac{\varepsilon_{t}^{j}}{\hat{\varepsilon}_{t}^{j}}\right)^{\frac{\tilde{\alpha}}{1-\tilde{\alpha}}}-1\right]\right\} h_{t}^{j}-h_{t+1}^{j} .
\end{aligned}
$$

Case 3. $\underline{\varepsilon}_{t}^{j} \leq \varepsilon_{t}^{j}<\hat{\varepsilon}_{t}^{j}$, where $\underline{\varepsilon}_{t}^{j} \equiv\left(h_{t}^{j}\right)^{\frac{1-\tilde{\alpha}}{\tilde{\alpha}}}\left[\frac{r_{d t}+\delta}{\tilde{\alpha} \tau^{j}\left(z^{j}\right)^{\tilde{\alpha}} R_{t}}\right]^{\frac{1}{\tilde{\alpha}}}$. In this case, the optimal loan and saving both are zero (inactive regime). So we have

$$
\begin{aligned}
l_{t}^{j} & =s_{t}^{j}=0, \\
k_{t}^{j} & =h_{t}^{j}, \\
d_{t}^{j} & =\tau^{j} R_{t}\left(z^{j} \varepsilon_{t}^{j} h_{t}^{j}\right)^{\tilde{\alpha}}+(1-\delta) h_{t}^{j}-h_{t+1}^{j} .
\end{aligned}
$$

Case 4. $\varepsilon_{\min } \leq \varepsilon_{t}^{j}<\underline{\varepsilon}_{t}^{j}$. In this case, the optimal loan is zero, and the optimal saving is an interior solution. We then have

$$
\begin{aligned}
l_{t}^{j} & =0, \\
s_{t}^{j} & =\left[1-\left(\frac{\varepsilon_{t}^{j}}{\underline{\varepsilon}_{t}^{j}}\right)^{\frac{\tilde{\alpha}}{1-\tilde{\alpha}}}\right] h_{t}^{j}, \\
k_{t}^{j} & =\left(\frac{\varepsilon_{t}^{j}}{\underline{\varepsilon}_{t}^{j}}\right)^{\frac{\tilde{\alpha}}{1-\tilde{\alpha}}} h_{t}^{j}, \\
d_{t}^{j} & =\tau^{j} R_{t}\left[z^{j} \varepsilon_{t}^{j}\left(\frac{\varepsilon_{t}^{j}}{\underline{\varepsilon}_{t}^{j}}\right)^{\frac{\tilde{\alpha}}{1-\tilde{\alpha}}} h_{t}^{j}\right]^{\tilde{\alpha}} \\
& +\left\{(1-\delta)+\left(\delta+r_{d t}\right)\left[1-\left(\frac{\varepsilon_{t}^{j}}{\underline{\varepsilon}_{t}^{j}}\right)^{\frac{\tilde{\alpha}}{1-\tilde{\alpha}}}\right]\right\} h_{t}^{j}-h_{t+1}^{j} .
\end{aligned}
$$


In each case, the optimal decision of $h_{t+1}^{j}$ satisfies the following Euler equation

$$
1=\beta \mathbf{E}_{t} \frac{\Lambda_{t+1}}{\Lambda_{t}} \int \frac{\partial V_{t+1}^{j}\left(h_{t+1}^{j}, \varepsilon_{t+1}^{j}\right)}{\partial h_{t+1}^{j}} d \mathbf{F}^{j}\left(\varepsilon_{t+1}^{j}\right),
$$

where

$$
\frac{\partial V_{t}^{j}\left(h_{t}^{j}, \varepsilon_{t}^{j}\right)}{\partial h_{t}^{j}}= \begin{cases}\Gamma_{t}^{j}\left(\varepsilon_{t}^{j}, h_{t}^{j}\right)\left(1+\theta^{j}\right)^{\tilde{\alpha}}+(1-\delta)-\left(\delta+r_{l t}\right) \theta^{j}, & \text { if } \varepsilon_{t}^{j} \geq \bar{\varepsilon}_{t}^{j} \\ \Gamma_{t}^{j}\left(\varepsilon_{t}^{j}, h_{t}^{j}\right)\left[\left(\varepsilon_{t}^{j} / \hat{\varepsilon}_{t}^{j}\right)^{\frac{\tilde{\alpha}}{1-\tilde{\alpha}}}\right]^{\tilde{\alpha}}+(1-\delta)-\left(\delta+r_{l t}\right)\left[\left(\varepsilon_{t}^{j} / \hat{\varepsilon}_{t}^{j}\right)^{\frac{\tilde{\alpha}}{1-\tilde{\alpha}}}-1\right], & \text { if } \hat{\varepsilon}_{t}^{j} \leq \varepsilon_{t}^{j}<\bar{\varepsilon}_{t}^{j} \\ \Gamma_{t}^{j}\left(\varepsilon_{t}^{j}, h_{t}^{j}\right)+(1-\delta), & \text { if } \underline{\varepsilon}_{t}^{j} \leq \varepsilon_{t}^{j}<\hat{\varepsilon}_{t}^{j} \\ \Gamma_{t}^{j}\left(\varepsilon_{t}^{j}, h_{t}^{j}\right)\left[\left(\varepsilon_{t}^{j} / \underline{\varepsilon}_{t}^{j}\right)^{\frac{\tilde{\alpha}}{1-\tilde{\alpha}}}\right]^{\tilde{\alpha}}+(1-\delta)+\left(\delta+r_{d t}\right)\left[1-\left(\varepsilon_{t}^{j} / \underline{\varepsilon}_{t}^{j}\right)^{\frac{\tilde{\alpha}}{1-\tilde{\alpha}}}\right], & \text { if } \varepsilon_{t}^{j}<\underline{\varepsilon}_{t}^{j}\end{cases}
$$

where $\Gamma_{t}^{j}\left(\varepsilon_{t}^{j}, h_{t}^{j}\right)=\tau^{j} R_{t}\left(z^{j} \varepsilon_{t}^{j}\right)^{\tilde{\alpha}} \tilde{\alpha}\left(h_{t}^{j}\right)^{\tilde{\alpha}-1}$. It is straightforward to show that under the i.i.d assumption of $\varepsilon_{t+1}^{j}, h_{t+1}^{j}$ is irrelevant to the idiosyncratic shocks. Denote the aggregate net worth as $H_{t}^{j}$. Then, we have $H_{t}^{j}=h_{t}^{j}$. Therefore, the cutoffs $\left\{\bar{\varepsilon}_{t}^{j}, \hat{\varepsilon}_{t}^{j}, \underline{\varepsilon}_{t}^{j}\right\}$ are independent of the idiosyncratic shocks as well.

\section{Appendix B. The Dynamic Model}

This section provides a summary of the equilibrium conditions in the dynamic model.

The equilibrium system consists of aggregate equilibrium conditions and sector-specific equilibrium conditions.

B.1. Sector-specific equilibrium conditions. We first summarize the sector-specific equilibrium relations for each sector $j \in\{s, p\}$.

The sectoral aggregate output $Y_{t}^{j}$ is given by

$$
Y_{t}^{j}=\left(\tilde{K}_{t}^{j}\right)^{1-\gamma}\left(N_{t}^{j}\right)^{\gamma}
$$

where $\gamma=(1-\alpha) \eta$.

The variable $\tilde{K}_{t}^{j}$ denotes the effective capital for sector $j$ and it is given by

$$
\begin{aligned}
\tilde{K}_{t}^{j} & =\int\left[z^{j} \varepsilon_{t}^{j} k_{t}^{j}\left(H_{t}^{j}, \varepsilon_{t}^{j}\right)\right]^{\tilde{\alpha}} d \mathbf{F}^{j}\left(\varepsilon_{t}^{j}\right) \\
& =\left(H_{t}^{j}\right)^{\tilde{\alpha}}\left\{\int_{\varepsilon_{\min }^{j}}^{\varepsilon_{t}^{j}}\left[z^{j} \varepsilon_{t}^{j}\left(\varepsilon_{t}^{j} / \underline{\varepsilon}_{t}^{j}\right)^{\frac{\tilde{\alpha}}{1-\tilde{\alpha}}}\right]^{\tilde{\alpha}} d \mathbf{F}^{j}\left(\varepsilon_{t}^{j}\right)+\int_{\underline{\varepsilon}_{t}^{j}}^{\hat{\varepsilon}_{t}^{j}}\left(z^{j} \varepsilon_{t}^{j}\right)^{\tilde{\alpha}} d \mathbf{F}^{j}\left(\varepsilon_{t}^{j}\right)\right. \\
& \left.+\int_{\hat{\varepsilon}_{t}^{j}}^{\bar{\varepsilon}_{t}^{j}}\left[z^{j} \varepsilon_{t}^{j}\left(\varepsilon_{t}^{j} / \hat{\varepsilon}_{t}^{j}\right)^{\frac{\tilde{\alpha}}{1-\tilde{\alpha}}}\right]^{\tilde{\alpha}} d \mathbf{F}^{j}\left(\varepsilon_{t}^{j}\right)+\left(1+\theta^{j}\right)^{\tilde{\alpha}} \int_{\bar{\varepsilon}_{t}^{j}}^{\varepsilon_{\max }^{j}}\left(z^{j} \varepsilon_{t}^{j}\right)^{\tilde{\alpha}} d \mathbf{F}^{j}\left(\varepsilon_{t}^{j}\right)\right\} .
\end{aligned}
$$


The sectoral labor demand $N_{t}^{j}$ is

$$
\begin{aligned}
N_{t}^{j} & =\tau^{j}\left(\frac{\gamma}{W_{t}}\right)^{\frac{1}{1-\gamma}} \int\left(z^{j} \varepsilon_{t}^{j} k_{t}^{j}\right)^{\tilde{\alpha}} d \mathbf{F}^{j}\left(\varepsilon_{t}^{j}\right) \\
& =\tau^{j}\left(\frac{\gamma}{W_{t}}\right)^{\frac{1}{1-\gamma}} \tilde{K}_{t}^{j}, j \in\{s, p\} .
\end{aligned}
$$

The sectoral capital input $K_{t}^{j}$ (which is different from the effective capital $\tilde{K}_{t}^{j}$ ) is given by

$$
\begin{aligned}
K_{t}^{j} & =\int k_{t}^{j}\left(H_{t}^{j}, \varepsilon_{t}^{j}\right) d \mathbf{F}^{j}\left(\varepsilon_{t}^{j}\right) \\
& =H_{t}^{j}\left[\int_{\varepsilon_{\min }^{j}}^{\underline{\varepsilon}_{t}^{j}}\left(\varepsilon_{t}^{j} / \underline{\varepsilon}_{t}^{j}\right)^{\frac{\tilde{\alpha}}{1-\tilde{\alpha}}} d \mathbf{F}^{j}\left(\varepsilon_{t}^{j}\right)+\int_{\underline{\varepsilon}_{t}^{j}}^{\hat{\varepsilon}_{t}^{j}} d \mathbf{F}^{j}\left(\varepsilon_{t}^{j}\right)\right. \\
& \left.+\int_{\hat{\varepsilon}_{t}^{j}}^{\tilde{\varepsilon}_{t}^{j}}\left(\varepsilon_{t}^{j} / \hat{\varepsilon}_{t}^{j}\right)^{\frac{\tilde{\alpha}}{1-\tilde{\alpha}}} d \mathbf{F}^{j}\left(\varepsilon_{t}^{j}\right)+\left(1+\theta^{j}\right) \int_{\bar{\varepsilon}_{t}^{j}}^{\varepsilon_{\max }^{j}} d \mathbf{F}^{j}\left(\varepsilon_{t}^{j}\right)\right] .
\end{aligned}
$$

The three cut-off productivity levels are given by

$$
\begin{aligned}
\underline{\varepsilon}_{t}^{j} & =\left(H_{t}^{j}\right)^{\frac{1-\tilde{\alpha}}{\tilde{\alpha}}}\left[\frac{r_{d t}+\delta}{\tilde{\alpha} \tau^{j}\left(z^{j}\right)^{\tilde{\alpha}} R_{t}}\right]^{\frac{1}{\tilde{\alpha}}}, \\
\hat{\varepsilon}_{t}^{j} & =\left(H_{t}^{j}\right)^{\frac{1-\tilde{\alpha}}{\tilde{\alpha}}}\left[\frac{r_{l t}+\delta}{\tilde{\alpha} \tau^{j}\left(z^{j}\right)^{\tilde{\alpha}} R_{t}}\right]^{\frac{1}{\tilde{\alpha}}}, \\
\bar{\varepsilon}_{t}^{j} & =\left[\left(1+\theta^{j}\right) H_{t}^{j}\right]^{\frac{1-\tilde{\alpha}}{\tilde{\alpha}}}\left[\frac{r_{l t}+\delta}{\tilde{\alpha} \tau^{j}\left(z^{j}\right)^{\tilde{\alpha}} R_{t}}\right]^{\frac{1}{\tilde{\alpha}}},
\end{aligned}
$$

The sectoral net worth $H_{t}^{j}$ is given by

$$
1=\beta \mathbf{E}_{t} \frac{\Lambda_{t+1}}{\Lambda_{t}} \int \frac{\partial V_{t+1}^{j}\left(h_{t+1}^{j}, \varepsilon_{t+1}^{j}\right)}{\partial h_{t+1}^{j}} d \mathbf{F}^{j}\left(\varepsilon_{t+1}^{j}\right),
$$

where

$$
\frac{\partial V_{t}^{j}\left(h_{t}^{j}, \varepsilon_{t}^{j}\right)}{\partial h_{t}^{j}}= \begin{cases}\Gamma_{t}^{j}\left(\varepsilon_{t}^{j}, h_{t}^{j}\right)\left(1+\theta^{j}\right)^{\tilde{\alpha}}+(1-\delta)-\left(\delta+r_{l t}\right) \theta^{j}, & \text { if } \varepsilon_{t}^{j} \geq \bar{\varepsilon}_{t}^{j} \\ \Gamma_{t}^{j}\left(\varepsilon_{t}^{j}, h_{t}^{j}\right)\left[\left(\varepsilon_{t}^{j} / \hat{\varepsilon}_{t}^{j}\right)^{\frac{\tilde{\alpha}}{1-\tilde{\alpha}}}\right]^{\tilde{\alpha}}+(1-\delta)-\left(\delta+r_{l t}\right)\left[\left(\varepsilon_{t}^{j} / \hat{\varepsilon}_{t}^{j}\right)^{\frac{\tilde{\alpha}}{1-\tilde{\alpha}}}-1\right], & \text { if } \hat{\varepsilon}_{t}^{j} \leq \varepsilon_{t}^{j}<\bar{\varepsilon}_{t}^{j} \\ \Gamma_{t}^{j}\left(\varepsilon_{t}^{j}, h_{t}^{j}\right)+(1-\delta), & \text { if } \underline{\varepsilon}_{t}^{j} \leq \varepsilon_{t}^{j}<\hat{\varepsilon}_{t}^{j} \\ \Gamma_{t}^{j}\left(\varepsilon_{t}^{j}, h_{t}^{j}\right)\left[\left(\varepsilon_{t}^{j} / \underline{\varepsilon}_{t}^{j}\right)^{\frac{\tilde{\alpha}}{1-\tilde{\alpha}}}\right]^{\tilde{\alpha}}+(1-\delta)+\left(\delta+r_{d t}\right)\left[1-\left(\varepsilon_{t}^{j} / \underline{\varepsilon}_{t}^{j}\right)^{\frac{\tilde{\alpha}}{1-\tilde{\alpha}}}\right], & \text { if } \varepsilon_{t}^{j}<\underline{\varepsilon}_{t}^{j}\end{cases}
$$

and $\Gamma_{t}^{j}\left(\varepsilon_{t}^{j}, h_{t}^{j}\right)=\tau^{j} R_{t}\left(z^{j} \varepsilon_{t}^{j}\right)^{\tilde{\alpha}} \tilde{\alpha}\left(h_{t}^{j}\right)^{\tilde{\alpha}-1}$.

The sectoral loans $L_{t}^{j}$ is given by

$$
L_{t}^{j}=\int l_{t}^{j}\left(h_{t}^{j}, \varepsilon_{t}^{j}\right) d \mathbf{F}^{j}\left(\varepsilon_{t}^{j}\right)=H_{t}^{j} \int_{\hat{\varepsilon}_{t}^{j}}^{\bar{\varepsilon}_{t}^{j}}\left[\left(\varepsilon_{t}^{j} / \hat{\varepsilon}_{t}^{j}\right)^{\frac{\tilde{\alpha}}{1-\tilde{\alpha}}}-1\right] d \mathbf{F}^{j}\left(\varepsilon_{t}^{j}\right)+\theta_{t}^{j} H_{t}^{j} \int_{\bar{\varepsilon}_{t}^{j}}^{\varepsilon_{\max }^{j}} d \mathbf{F}^{j}\left(\varepsilon_{t}^{j}\right) .
$$


The sectoral saving $S_{t}^{j}$ is given by

$$
S_{t}^{j}=H_{t}^{j} \int_{\varepsilon_{\min }^{j}}^{\underline{\varepsilon}_{t}^{j}}\left[1-\left(\underline{\varepsilon}_{t}^{j}\right)^{-\frac{\tilde{\alpha}}{1-\tilde{\alpha}}}\left(\varepsilon_{t}^{j}\right)^{\frac{\tilde{\alpha}}{1-\tilde{\alpha}}}\right] d \mathbf{F}^{j}\left(\varepsilon_{t}^{j}\right) .
$$

The sectoral TFP $A_{t}^{j}$ is given by

$$
\begin{aligned}
A_{t}^{j} & =\frac{Y_{t}^{j}}{\left[\left(K_{t}^{j}\right)^{\alpha}\left(N_{t}^{j}\right)^{1-\alpha}\right]^{\eta}} \\
& =\left(z^{j}\right)^{\alpha}\left\{\int\left[\frac{\varepsilon_{t}^{j} k_{t}^{j}\left(H_{t}^{j}, \varepsilon_{t}^{j}\right)}{K_{t}^{j}}\right]^{\tilde{\alpha}} d \mathbf{F}^{j}\left(\varepsilon_{t}^{j}\right)\right\}^{1-\gamma} .
\end{aligned}
$$

B.2. Aggregate equilibrium conditions. Aggregate output is given by

$$
Y_{t}=\sum_{j=\{s, p\}} Y_{t}^{j}
$$

Aggregate employment satisfies

$$
N_{t}=\sum_{j=\{s, p\}} N_{t}^{j}=1
$$

Aggregate capital stock satisfies

$$
K_{t} \equiv \sum_{j=\{s, p\}} K_{t}^{j}
$$

Credit market clearing implies that

$$
K_{t}=\sum_{j=\{s, p\}} H_{t}^{j}
$$

Aggregate resource constraint implies that

$$
C_{t}+K_{t+1}-(1-\delta) K_{t}=Y_{t}
$$

Aggregate TFP $A_{t}$ is given by

$$
A_{t}=\frac{Y_{t}}{\left(K_{t}^{\alpha} N_{t}^{1-\alpha}\right)^{\eta}}
$$

Returns on effective capital is

$$
R_{t}=(1-\gamma)\left(\frac{\gamma}{W_{t}}\right)^{\frac{\gamma}{1-\gamma}}
$$

The interest rate gap implies that

$$
r_{l t}=r_{d t}+\phi
$$




\section{Appendix C. Steps for Solving the Steady State}

This appendix presents the procedure for solving the steady state. From the definitions of cutoffs $\left\{\underline{\varepsilon}^{j}, \hat{\varepsilon}^{j}, \bar{\varepsilon}^{j}\right\}$, we can solve for $\underline{\varepsilon}^{j}, \hat{\varepsilon}^{j}$, and $\bar{\varepsilon}^{j}$ as functions of $r_{d}, R$, and $H^{j}$. From (B.2), (B.4), and (B.10), we can solve for the ratios $\frac{\tilde{K}^{j}}{\left(H^{j}\right)^{\alpha}}, \frac{K^{j}}{H^{j}}, \frac{L^{j}}{H^{j}}$, and $\frac{S^{j}}{H^{j}}$, which are given by

$$
\begin{aligned}
& \frac{\tilde{K}^{j}}{\left(H^{j}\right)^{\tilde{\alpha}}}=\int_{\varepsilon_{\min }^{j}}^{\varepsilon_{t}^{j}}\left[z^{j} \varepsilon^{j}\left(\varepsilon^{j} / \underline{\varepsilon}^{j}\right)^{\frac{\tilde{\alpha}}{1-\tilde{\alpha}}}\right]^{\tilde{\alpha}} d \mathbf{F}^{j}\left(\varepsilon^{j}\right)+\int_{\underline{\varepsilon}^{j}}^{\hat{\varepsilon}^{j}}\left(z^{j} \varepsilon^{j}\right)^{\tilde{\alpha}} d \mathbf{F}^{j}\left(\varepsilon^{j}\right) \\
& +\int_{\hat{\varepsilon}^{j}}^{\bar{\varepsilon}^{j}}\left[z^{j} \varepsilon^{j}\left(\varepsilon^{j} / \hat{\varepsilon}^{j}\right)^{\frac{\tilde{\alpha}}{1-\tilde{\alpha}}}\right]^{\tilde{\alpha}} d \mathbf{F}^{j}\left(\varepsilon^{j}\right)+\left(1+\theta^{j}\right)^{\tilde{\alpha}} \int_{\bar{\varepsilon}^{j}}^{\varepsilon_{j}^{j}}\left(z^{j} \varepsilon^{j}\right)^{\tilde{\alpha}} d \mathbf{F}^{j}\left(\varepsilon^{j}\right), \\
& \frac{K^{j}}{H^{j}}=\int_{\varepsilon_{\min }^{j}}^{\varepsilon^{j}}\left(\varepsilon^{j} / \underline{\varepsilon}^{j}\right)^{\frac{\tilde{\alpha}}{1-\tilde{\alpha}}} d \mathbf{F}^{j}\left(\varepsilon^{j}\right)+\int_{\underline{\varepsilon}^{j}}^{\hat{\varepsilon}^{j}} d \mathbf{F}^{j}\left(\varepsilon^{j}\right) \\
& +\int_{\hat{\varepsilon}^{j}}^{\bar{\varepsilon}^{j}}\left(\varepsilon^{j} / \hat{\varepsilon}^{j}\right)^{\frac{\tilde{\alpha}}{1-\tilde{\alpha}}} d \mathbf{F}^{j}\left(\varepsilon^{j}\right)+\left(1+\theta^{j}\right) \int_{\bar{\varepsilon}^{j}}^{\varepsilon_{\max }^{j}} d \mathbf{F}^{j}\left(\varepsilon^{j}\right), \\
& \frac{L^{j}}{H^{j}}=\int_{\hat{\varepsilon}^{j}}^{\bar{\varepsilon}^{j}}\left[\left(\varepsilon^{j} / \hat{\varepsilon}^{j}\right)^{\frac{\alpha}{1-\tilde{\alpha}}}-1\right] d \mathbf{F}^{j}\left(\varepsilon^{j}\right)+\theta^{j} \int_{\bar{\varepsilon}^{j}}^{\varepsilon_{\max }^{j}} d \mathbf{F}^{j}\left(\varepsilon^{j}\right), \\
& \frac{S^{j}}{H^{j}}=\int_{\varepsilon_{\min }^{j}}^{\underline{\varepsilon}^{j}}\left[1-\left(\varepsilon^{j} / \underline{\varepsilon}^{j}\right)^{\frac{\tilde{\alpha}}{1-\tilde{\alpha}}}\right] d \mathbf{F}^{j}\left(\varepsilon^{j}\right), \text { for } j \in\{s, p\} .
\end{aligned}
$$

Then we can express $\left\{\tilde{K}^{j}, K^{j}, L^{j}, S^{j}\right\}$ as functions of $r_{d}, R$, and $H^{j}$.

Since labor supply is fixed at $N=1$, we can compute the equilibrium wage rate from the labor demand function

$$
N=\left(\frac{\gamma}{W}\right)^{\frac{1}{1-\gamma}} \sum_{j \in\{s, p\}} \tau^{j} \tilde{K}^{j}=1
$$

The sectoral labor inputs are given by

$$
N^{j}=\frac{\tau^{j} \tilde{K}^{j}}{\tau^{s} \tilde{K}^{s}+\tau^{p} \tilde{K}^{p}}, \quad j \in\{s, p\} .
$$

Given the sectoral labor and effective capital inputs, the sectoral output can be solved. In particular, we have $Y^{j}=\left(\tilde{K}^{j}\right)^{1-\gamma}\left(N^{j}\right)^{\gamma}$.

Aggregate output is given by $Y=\sum_{j \in\{s, p\}} Y^{j}$. Aggregate consumption can be obtained from the resource constraint (B.18).

Finally, we pin down the steady-state values of $H^{j}, r_{d}$, and $R$ using equations (B.8), (B.17), and (B.20). 


\section{REFERENCES}

Arellano, M. And S. Bond (1991): "Some Tests of Specification for Panel Data: Monte Carlo Evidence and an Application to Employment Equations," Review of Economic Studies, 58, 277-297.

Bai, C.-E., D. D. Li, Z. TAO, And Y. Wang (2000): "A Multitask Theory of State Enterprise Reform," Journal of Comparative Economics, 28, 716-738.

BanerJee, A. And E. Duflo (2005): "Growth Theory through the Lens of Development Economics," in Handbook of Economic Growth, ed. by P. Aghion and S. N. Durlauf, Amsterdam: Elsevier, chap. 7, 473-552.

Banerjee, A. V. And B. Moll (2010): "Why does misallocation persist?" American Economic Journal: Macroeconomics, 2, 189-206.

Bartelsman, E., J. Haltiwanger, and S. Scarpetta (2013): "Cross-country differences in productivity: The role of allocation and selection," The American Economic Review, 103, 305-334.

Bleck, A. And X. Liu (2018): "Credit Expansion and Credit Misallocation," Journal of Monetary economics, 94, 27-40.

Brandt, L., C.-T. Hsieh, And X. Zhu (2008): "Growth and Structural Transformation in China," in China's Great Economic Transformation, ed. by L. Brandt and T. G. Rawski, Cambridge, UK: Cambridge University Press, 683-728.

Brandt, L., T. Tombe, And X. Zhu (2013): "Factor market distortions across time, space and sectors in China," Review of Economic Dynamics, 16, 39-58.

Brandt, L. AND X. Zhu (2000): "Redistribution in a Decentralized Economy," Journal of Political Economy, 108, 422-439.

- (2010): “Accounting for China's growth," Institute for the Study of Labor Discussion Paper No. 4764.

Buera, F. J., J. P. Kaboski, And Y. Shin (2011): "Finance and Development: A Tale of Two Sectors," American Economic Review, 101, 1964-2002.

Buera, F. J., B. Moll, And Y. Shin (2013): "Well-intended policies," Review of Economic Dynamics, 16, 216-230.

Caggese, A. And V. Cuñat (2013): "Financing constraints, firm dynamics, export decisions, and aggregate productivity," Review of Economic Dynamics, 16, 177-193.

Chang, C., K. Chen, D. F. Waggoner, And T. Zha (2015a): "Trends and Cycles in China's Macroeconomy," in NBER Macroeconomics Annual 2015 (forthcoming), ed. by M. Eichenbaum and J. Parker, University of Chicago Press.

Chang, C., Z. Liu, And M. M. Spiegel (2015b): "Capital Controls and Optimal Chinese Monetary Policy," Journal of Monetary Economics, 74, 1-15. 
Chang, C., Z. Liu, M. M. Spiegel, And J. Zhang (2019): "Reserve Requirements and Optimal Chinese Stabilization Policy," Journal of Monetary Economics, 103, 33-51.

Cole, H. L., J. Greenwood, And J. M. Sanchez (2016): "Why Doesn't Technology Flow From Rich to Poor Countries?" Econometrica, 84, 1477-1521.

Cong, L. W., H. Gao, J. Ponticelli, and X. Yang (2018): "Credit Allocation under Economic Stimulus: Evidence from China," Unpublished Manuscript, University of Chicago Booth School of Business.

GaO, H., H. Ru, R. M. Townsend, and X. Yang (2017): "Rise of Bank Competition: Evidence from Banking Deregulation in China," Unpublished manuscript.

Gilchrist, S., J. W. Sim, AND E. ZAKRAJŠEK (2013): "Misallocation and financial market frictions: Some direct evidence from the dispersion in borrowing costs," Review of Economic Dynamics, 16, 159-176.

Gopinath, G., S. Kalemli-ÖZcan, L. Karabarbounis, and C. Villegas-Sanchez (2017): "Capital Allocation and Productivity in South Europe," Quarterly Journal of Economics, 132, 1915-1967.

Hsieh, C.-T. And P. J. Klenow (2009): "Misallocation and Manufacturing TFP in China and India," The Quarterly Journal of Economics, 124, 1403-1448.

JEOnG, H. And R. M. Townsend (2007): "Sources of TFP growth: occupational choice and financial deepening," Economic Theory, 32, 179-221.

Li, X., X. LiU, And Y. WAng (2015): “A Model of China's State Capitalism," Unpuglished manuscript, Hong Kong University of Science and Technology.

Lin, J. Y., F. CAI, AND Z. Li (1998): "Competition, policy burdens, and state-owned enterprise reform," The American Economic Review, 88, 422-427.

LiN, J. Y. AND G. TAN (1999): "Policy burdens, accountability, and the soft budget constraint," The American Economic Review, 89, 426-431.

Liu, Z., M. M. Spiegel, And J. Zhang (2019): "Optimal Capital Account Liberalization in China," Federal Reserve Bank of San Francisco Working Paper 2018-10.

Liu, Z. AND P. WAng (2014): "Credit Constraints and Self-Fulfilling Business Cycles," American Economic Journal: Macroeconomics, 6, 32-69.

Midrigan, V. And D. Y. Xu (2014): "Finance and Misallocation: Evidence from PlantLevel Data," American Economic Review, 104, 422-458.

Moll, B. (2014): "Productivity Losses from Financial Frictions: Can Self-Financing Undo Capital Misallocation?" American Economic Review, 104, 3186-3221.

Reis, R. (2013): "The Portugese Slump and Crash and the Euro Crisis," Brookings Papers on Economic Activity, 44, 143-210. 
Restuccia, D. And R. Rogerson (2008): "Policy distortions and aggregate productivity with heterogeneous establishments," Review of Economic dynamics, 11, 707-720.

- (2013): "Misallocation and productivity," Review of Economic Dynamics, 16, 1-10.

- (2017): "The Causes and Costs of Misallocation," Journal of Economic Perspectives, 31, 151-174.

Song, Z. And C.-T. Hsieh (2015): "Grasp the Large, Let Go of the Small: The Transformation of the State Sector in China," NBER Working Paper No. 21006.

Song, Z., K. Storesletten, And F. Zilibotti (2011): "Growing Like China," The American Economic Review, 101, 196-233.

Wang, H., H. WAng, L. WAng, And H. Zhou (2016): "Shadow Banking: China's Dual-Track Interest Rate Liberalization," Unfinished Manuscript, Tsinghua University.

Zhu, X. (2012): "Understanding China's Growth: Past, Present, and Future," Journal of Economic Perspectives, 26, 103-124. 